\title{
Radiomics as a New Frontier of Imaging for Cancer Prognosis: A Narrative Review
}

\author{
Alfonso Reginelli ${ }^{1}$, Valerio Nardone ${ }^{1, *}$, Giuliana Giacobbe ${ }^{1,2}$, Maria Paola Belfiore ${ }^{1}$, Roberta Grassi ${ }^{1}$, \\ Ferdinando Schettino ${ }^{1}$, Mariateresa Del Canto ${ }^{1}$, Roberto Grassi ${ }^{1,2}$ and Salvatore Cappabianca ${ }^{1}$ \\ 1 Section of Radiology and Radiotherapy, Department of Precision Medicine, University of Campania \\ “L. Vanvitelli", 80138 Naples, Italy; alfonso.reginelli@unicampania.it (A.R.); gi.giacobbe10@gmail.com (G.G.); \\ mariapaolabelfiore@libero.it (M.P.B.); roberta.grassi@libero.it (R.G.); ferdinandoschettino1@libero.it (F.S.); \\ mariateresadelcanto@libero.it (M.D.C.); roberto.grassi1@libero.it (R.G.); \\ salvatore.cappabianca@unicampania.it (S.C.) \\ 2 Italian Society of Medical and Interventional Radiology, SIRM Foundation, 20122 Milan, Italy \\ * Correspondence: Valerio.nardone@unicampania.it
}

check for updates

Citation: Reginelli, A.; Nardone, V.; Giacobbe, G.; Belfiore, M.P.; Grassi, R.; Schettino, F.; Del Canto, M.; Grassi, R.; Cappabianca, S. Radiomics as a New Frontier of Imaging for Cancer Prognosis: A Narrative Review. Diagnostics 2021, 11, 1796. https:/ / doi.org/10.3390/diagnostics11101796

Academic Editors: Ahmet F. Coskun and Andor W.J.M. Glaudemans

Received: 4 August 2021

Accepted: 23 September 2021

Published: 29 September 2021

Publisher's Note: MDPI stays neutral with regard to jurisdictional claims in published maps and institutional affiliations.

Copyright: (c) 2021 by the authors. Licensee MDPI, Basel, Switzerland. This article is an open access article distributed under the terms and conditions of the Creative Commons Attribution (CC BY) license (https:// creativecommons.org/licenses/by/ $4.0 /)$.

\begin{abstract}
The evaluation of the efficacy of different therapies is of paramount importance for the patients and the clinicians in oncology, and it is usually possible by performing imaging investigations that are interpreted, taking in consideration different response evaluation criteria. In the last decade, texture analysis (TA) has been developed in order to help the radiologist to quantify and identify parameters related to tumor heterogeneity, which cannot be appreciated by the naked eye, that can be correlated with different endpoints, including cancer prognosis. The aim of this work is to analyze the impact of texture in the prediction of response and in prognosis stratification in oncology, taking into consideration different pathologies (lung cancer, breast cancer, gastric cancer, hepatic cancer, rectal cancer). Key references were derived from a PubMed query. Hand searching and clinicaltrials.gov were also used. This paper contains a narrative report and a critical discussion of radiomics approaches related to cancer prognosis in different fields of diseases.
\end{abstract}

Keywords: texture analysis; radiomics; artificial intelligence; cancer; radiogenomics; radiology

\section{Introduction}

Surgery, radiotherapy, chemotherapy and immunotherapy represent the mainstream of anticancer therapies, that can be used either alone or in combination.

The evaluation of their efficacy is of paramount importance in oncology, and it is usually made possible by performing imaging investigations. The different imaging data sets are then evaluated by the radiologist and the response is usually classified following the response evaluation criteria [1,2].

More recently, radiologists have developed a structured report with the aim to integrate subjective considerations with quantitative and objective assessments of the extent of the lesions in order to summarize and facilitate the clinical management of cancer patients [3-5].

In the last decade, a new technique, called texture analysis (TA), has been developed in order to help the radiologist to quantify and identify parameters related to tumor heterogeneity which cannot be appreciated by the naked eye [6-8]. This analysis can use different mathematical models that are able to extract quantitative parameters from regions of interest (ROIs) of selected volumes, that are called texture features [9-12]. TA workflow consists of different processes, such as the acquisition of the imaging, delineation of the ROIs, extraction of features and statistical correlation with different endpoints, and its use is being investigated in several fields [13-20].

More recently, a different approach of dynamic TA has been developed, that analyses the variations in TA features in subsequent imaging evaluations. This approach is usually called delta texture analysis or delta radiomics (D-TA) [21-24]. 
With this method, it is possible to investigate the role of TA variations after therapy (usually chemotherapy or radiotherapy) or shortly after the beginning of therapy.

Both TA and D-TA features can provide imaging biomarkers that can be used to discriminate the prognosis (prognostic parameters) and/or to predict the response to specific therapies (predictive parameters).

Herein, we will discuss the impact of TA in the prediction of response and in the prognosis stratification of different anticancer strategies, focusing on breast cancer, lung cancer, gastric cancer, liver cancer and rectal cancer, as these diseases were better characterized in TA literature, and we will provide a summary of other cancer TA. Following a literature search, we will provide a narrative overview of these topics.

\section{Texture Analysis and Prognosis-Focus on Lung Cancer}

Lung cancer represents one of the most common malignancy and the leading cause of cancer death [25]. Surgery or stereotactic radiotherapy (for unfit patients) are recommended for patients at the early stage of disease, whereas a combination of different strategies, including surgery, radiotherapy, chemotherapy and immunotherapy is used in locally advanced or metastatic diseases [26,27].

Medical imaging is of paramount importance in all the phases of the clinical management of lung cancer patients, either in diagnosis, during the different therapies in order to evaluate their efficacy and in the follow up [28-34].

TA is usually performed on computed tomography (CT) and positron emission tomography (PET), as these techniques have been widely used for lung cancer patients [35-41], whereas US and MRI are not currently used in the clinical management of lung cancer patients.

$\mathrm{CT}$ provides anatomical characteristics of the lung cancer lesions and the surrounding organs, whereas PET can provide molecular and metabolic information on the same structures.

We will focus on TA endpoints that include tumor response assessments and prognosis prediction.

Tumor response assessment in lung cancer is usually based on RECIST criteria [1] and it is divided into four classes: complete response, partial response, stable disease and progression of disease. Cook et al. showed that different parameters in TA analysis, based on PET, such as contrast, coarseness and busyness showed good statistical correlation with RECIST evaluation and outperformed SUV based parameters after chemoradiotherapy [42]. Dong et al., conversely, showed that early changes in texture features showed a higher specificity and sensitivity to classical parameters, such as coefficient of variation and MTV [43]. CT-based TA has been applied in the prediction of pathological response by Coroller et al. [44], who analyzed a cohort of 127 locally advanced lung cancer patients undergoing neoadjuvant chemoradiation before surgery. The authors found that tumors not responsive to chemoradiation had a rounder shape and a heterogeneous texture. In another investigation, the same authors observed that [45] TA, calculated on lymphonodes, had higher correlation with residual disease than TA obtained from the primary tumor.

For prognosis prediction, both overall survival and progression-free survival analyses are included.

Different PET-based TA parameters have been associated with overall survival, such as higher contrast [46], higher tumor heterogeneity [47] and higher tumor dissimilarity [48].

As above, D-TA features have been tested in this setting with promising results [49].

Similarly, radiomics features calculated on $\mathrm{CT}$, such as shape, intensity and texture features, can improve the prognosis stratification when combined with conventional clinical features, such as age, sex, performance status [50,51].

Paul et al. investigated dynamic parameters such as reduction in mean Hounsfield Unit (HU) obtained through the course of radiotherapy (D-TA). They were significantly related to overall survival [52].

Other authors have investigated the prediction either locoregional or distant recurrence after treatment. 
Pyka et al. investigated the correlation of TA features in lung cancer patients treated with radiotherapy and found that entropy and correlation outperformed SUV metrics in the prediction of recurrences [53].

Mattonen et al., contrarily, compared the radiologist and the TA features in the correct prediction of recurrence after stereotactic radiotherapy, and found that TA features had a lower classification error rate (24\% versus $35 \%$ ) [54].

The same authors applied the TA analysis to the penumbra region - that is, the region that extended outward $10 \mathrm{~mm}$ from the tumor surface. The authors discovered a significant correlation with recurrence prediction and highlight the analysis of the peritumoral region which, in the future, will be correlated with the immunotherapy response [55].

Krarup et al., on the other hand, tried to validate promising TA features calculated on PET in patients undergoing chemoradiotherapy for locally advanced lung cancer and found that the pre-selected TA features were not significantly correlated with PFS [56]. This negative study is noteworthy as it highlights the importance of the variations in technical parameters and the concerns for stability and reliability of TA features for their use in the clinical setting.

Finally, it is of great interest to report two meta-analyses recently published in the field of prognosis and lung cancer. The analysis by van Laar et al. [57] concluded that the only factors affecting survival in stage III lung cancer are tumor-size and nodal-size related factors. Kothari et al. [58], again, analyzed the prognostic value of the radiomics model in lung cancer and found significant heterogeneity among the studies $\left(\mathrm{I}^{2}=70.3 \%\right)$.

Specifically, Van Laar [57] selected 11,996 results (including 519 duplicates) for his meta-analysis and after cross-reference searching, included a total of 65 publications, with 26 individual CT-related prognostic factors for OS of patients with stage III NSCLC described. The results show that tumor diameter is prognostic for patients with stage IIIB NSCLC. In contrast, with regard to tumor volume, the included data proved too heterogeneous to draw definitive conclusions about tumor volume as a prognostic factor for this subset of patients.

In their meta-analysis, conversely, Kothari et al. [58] selected 2747 articles identifying 55 data sets and 6223 patients that were then included. Significant heterogeneity in the methodology used for feature selection and model development was demonstrated in this study. Twenty-six datasets measured the performance of radiomics-based models in predicting OS using a C index that ranged from 0.34 to 0.86 . Seven data sets used the AUC, which ranged from 0.69 to 0.96 . Twelve data sets with a Tripod analysis type of $2 \mathrm{a}$ or higher reported both a C-index and a 95\% CI (or standard deviation or standard error) and were included in the meta-analysis. The random-effects estimate was 0.57 (95\% CI 0.53 to 0.62 ). There is significant heterogeneity $\left(\mathrm{I}^{2}=70.3 \%\right)$.

In conclusion, TA in lung cancer has, to date, demonstrated modest prognostic capabilities. Future research should aim at optimizing and standardizing TA features, work on feature selection and model development, in order to improve this approach. Currently, several prospective observational studies are accruing lung cancer patients with different endpoints, including the development of radiomics models based on CT images to diagnose malignant nodules early. These models are able to discriminate the different types of lung cancer, correlate imaging to genetic and biomolecular characterization and stratify the prognosis of lung cancer patients (see Table 1). 
Table 1. Registered Clinical trials investigating Radiomics approach in Oncology.

\begin{tabular}{|c|c|c|c|}
\hline NCT Number & Study Phase & Disease Stage & Trial Design \\
\hline NCT03709186 & Observational & Breast Cancer & $\begin{array}{l}\text { Evaluation of radiomic markers in breast tumors to predict metastatic } \\
\text { risk based on radiomic features following primary therapy with } \\
\text { imaging techniques (DCE-MRI and DWI-MRI). }\end{array}$ \\
\hline NCT03038568 & Observational & Colorectal Cancer Metastatic & $\begin{array}{l}\text { Measurements of tumor differences vary with slight changes in CT scan } \\
\text { parameters. Reproducible radiomic features can be extracted for } \\
\text { abdominal tumors, and specifically colorectal liver metastases. }\end{array}$ \\
\hline NCT01585545 & Observational & Lung Cancer & $\begin{array}{l}\text { To evaluate relationships between multiparametric imaging biomarkers } \\
\text { (CT, PET/CT, MRI) and genetic analysis in NSCLC patients. }\end{array}$ \\
\hline NCT04315753 & Observational & Lung Cancer & $\begin{array}{l}\text { Analysis of the role of molecular and cellular biomarkers (exosomes } \\
\text { antigens, circulating tumor cells-CTCs, panel of mutations in circulating } \\
\text { free DNA) and radiomic signature. }\end{array}$ \\
\hline NCT04323579 & Observational & Lung Cancer & $\begin{array}{l}\text { CLEARLY will focus on validation of a multifactorial "bio-radiomic" } \\
\text { protocol for early diagnosis of lung cancer that combines circulating } \\
\text { biomarkers and radiomic analysis. }\end{array}$ \\
\hline NCT04364776 & Observational & Lung Cancer & $\begin{array}{l}\text { An Observational Study on Computed Tomography as an Image-based } \\
\text { Predictive Marker of Response to Chemoradiation Followed by } \\
\text { Durvalumab in Stage III Unresectable Non-small Cell Lung Cancer } \\
\text { (NSCLC). }\end{array}$ \\
\hline NCT03787667 & Observational & Colorectal Cancer & $\begin{array}{l}\text { This study is to collect and analyze data of radiomics (on enhanced CT } \\
\text { or MRI) of primary site or metastasis of colorectal cancer aiming to } \\
\text { make a precise preoperative diagnosis and long-term prognosis } \\
\text { evaluation. }\end{array}$ \\
\hline NCT03872362 & Observational & Lung Cancer & $\begin{array}{l}\text { The project aims to develop and validate radiomics models based on CT } \\
\text { images to identify malignant nodules and then to discriminate the } \\
\text { different types of lung adenocarcinoma in patients with pulmonary } \\
\text { nodules. }\end{array}$ \\
\hline NCT03198975 & Observational & Hepatocellular Carcinoma & $\begin{array}{l}\text { The aim of this prospective study is to develop a machine } \\
\text { learning-based model for preoperative prediction of MVI by extracting } \\
\text { high-dimensional magnetic resonance (MR) image features. }\end{array}$ \\
\hline NCT03679936 & Observational & Lung Cancer & $\begin{array}{l}\text { The purpose of this study is correlate the imaging findings with } \\
\text { genomics and histopathological features of newly diagnosed non-small } \\
\text { cell lung cancer (NSCLC). }\end{array}$ \\
\hline NCT04457700 & Observational & Breast Cancer & $\begin{array}{l}\text { This study aimed to assess the performance of CT-based radiomics in } \\
\text { evaluating the response and predicting pCR of metastatic lymph nodes } \\
\text { after NAC in breast cancer patients. }\end{array}$ \\
\hline NCT04553601 & Interventional & Lung Cancer & $\begin{array}{l}\text { To assess the potential usefulness of radiogenomics for tumor driving } \\
\text { genes heterogeneity in non-small cell lung cancer. }\end{array}$ \\
\hline NCT04320030 & Interventional & Breast Cancer & $\begin{array}{l}\text { This phase II study is assessing the correlation between } \\
\text { M1/M2 macrophage polarization determined by tumor } \\
\text { immunohistochemistry analysis and [18F]DPA-714 PET/CT binding } \\
\text { (qualitative and texture analysis) in patients with operable triple } \\
\text { negative breast cancer. }\end{array}$ \\
\hline NCT01959490 & Interventional & Breast Cancer & $\begin{array}{l}\text { Next Generation Sequencing and radiomics to Evaluate Breast Cancer } \\
\text { Subtypes and Genomic Predictors of Response to Therapy in the } \\
\text { Preoperative Setting for Stage II-III Breast Cancer. }\end{array}$ \\
\hline NCT02439086 & Interventional & Rectal Cancer & Prediction of complete response in PET and MRI texture analysis. \\
\hline
\end{tabular}

\section{Texture Analysis and Prognosis-Focus on Breast Cancer}

Breast cancer represents the most common malignancy in women [25], and early detection with mammography screening has been shown to have a great impact on survival $[59,60]$. While ultrasonography (US) is widely used for screening purposes, MRI in recent years is increasingly being used for high-risk women, as well as for staging, assessing curative effect and monitoring recurrence [61-63].

Breast cancer prognosis relies on immunohistochemical biomarkers, including estrogen receptor (ER), progesterone receptor (PR), human epidermal growth factor receptor 2 (HER2) and Ki-67 as substitutive molecular subtype [64,65]. 
In breast cancer research, the use of radiomics combined with multiple imaging modalities, clinical information and machine learning methods are under investigation, not only to detect malignant lesions and discriminating tumor grade, but also for identifying prognostic factors; for instance, the response to neoadjuvant chemotherapy (NAC) as well as the risk of tumor recurrence [66], similar to other settings [67-71].

Following the aim of the review, we will focus on papers dealing with TA correlation with prognosis, the assessment of responses to therapies and the prediction of recurrences, using the imaging modalities mainly used in breast cancer clinical management (US and MRI).

TA is able to offer large potential data to define the biological features of tumors for precision medicine [72]. Radiogenomics represents a specific evolution of radiomics that uses imaging capabilities to non-invasively identify or predict tumor-specific genomic alterations [73].

The biopsy of the suspected breast lesion is today the gold standard for the characterization of breast cancer; however, it evaluates only the sampled section of a heterogeneous tumor [74] and is currently not repeated for recurrent tumors. Radiogenomics can potentially evaluate the entire tumor load with the possibility of providing a non-invasive diagnosis and to closely monitor the characteristics of the lesions [75-79]. The combination of quantitative radiomics features with histological, clinical, and genomic data may represent a valid possibility for clinicians to develop patient-centered treatments [72,80-82].

Holli et al. [83], as well as Waugh et al. [84], found a correlation with entropy calculated on MRI with the differentiation between lobular and ductal carcinoma.

Other authors have investigated the potential to predict the molecular subtypes of breast cancer [85-87] or with tumor grade [88,89].

Braman et al. developed an MRI-based model that was able to identify different subtypes of HER2+ breast cancer patients [90]. This model could also predict response to neoadjuvant HER2 targeted therapy. It is important to note that molecular characteristics of breast cancer can be modified under the pressure of several factors such as systemic therapies, radiotherapy and so on [91,92]. Despite that, the patients usually do not repeat biopsies in the clinical management of recurrent disease, so that TA analysis, based on noninvasive imaging, such as MRI, CT can be useful to measure these molecular characteristics and to tailor the therapeutic strategies.

Other investigators have analyzed the risk of positive sentinel or axillary lymph nodes with different approaches and accuracies [93-95].

More recently, Chai et al. [96] used 3T DCE-MRI to extract TA features that showed an accuracy of 0.86 and an AUC of 0.91 for the prediction of axillary nodes. Liu et al. [97], again, performed a prospective study investigating the use of different models to predict the same endpoint and found that the model combining clinical information and TA parameters showed the best AUC (0.763).

Zheng et al. also [98] used deep learning radiomics with conventional US and shear wave elastography to predict the presence of axillary metastasis (AUC 0.902) and to discriminate between low and heavy burden of axillary disease (AUC 0.905). According to these studies, in the near future TA could support clinical decision-making, avoiding invasive procedures to the axilla.

Another field of investigation is the assessment of the response to neoadjuvant chemotherapy, which represents the most employed pre-operative strategy for breast cancer patients, with about half of the patients achieving a complete pathological response (pCR).

In this setting, several authors have correlated TA features calculated on MRI to predict pCR [99]. Braman et al. [100] used DCE-MRI imaging extracted from both tumoral and peritumoral regions, obtaining an AUC of $78 \%$ for the training dataset and $74 \%$ for the validation dataset. Drukker et al. [101], obtained similar prediction results of pCR (82\%) and lymphonodal status (72\%), with the same imaging technique (DCE-MRI).

Parikh et al. [102], contrarily, compared TA calculated on T2-weighted and contrastenhanced T1, weighted to assess $\mathrm{pCR}$, and found that T2-w showed higher sensitivity 
(87.5\% vs. 50\%). Kim et al. [103] also used both DCE-MRI and DCE-Ultrasonography and found that both methods showed good sensitivity for pCR (respectively, 81\% versus 71\%).

Finally, TA has been tested in the prediction of recurrences with several approaches, mostly with MRI imaging. Huang et al. [95] have used both MRI and PET/CT TA and found an AUC of $75 \%$ and $68 \%$, respectively, for disease-free survival (DFS) at 1 and 2 years. Park et al. [104] also found that the inclusion of TA features on MRI improved the DFS estimation on Cox analysis.

Li et al., contrarily, found that TA features calculated on DCE-MRI [105] were significantly associated with several clinical, histopathologic and genomic data and were able to discriminate between patients with good and poor prognosis, with an AUC of $88 \%$.

In conclusion radiomics in breast cancer has mainly focused on early identification of prognostic factors such as response to neo-adjuvant chemoradiation therapy (100-105) and monitoring of recurrence [61-63].

Specifically, one study [100] investigated a novel combined intratumoral and peritumoral radiomic approach for $\mathrm{pCR}$ prediction; it combined textural features extracted from a tumor and its immediate environment using routine DCE-MRI. Indeed, peritumoral radiomics have been shown to contribute to the successful prediction of $\mathrm{PCR}$ from pretreatment imaging. Furthermore, it has been found that the radiomic features most predictive of response appear to vary as a function of tumor molecular subtype.

In another study [90], a combination of peritumoral and intratumoral features appears to identify intrinsic molecular subtypes of HER2+ breast cancers from imaging, offering insights into the immune response in the peritumoral environment and suggesting the potential benefit for treatment guidance.

Correlations between radiomics and histological type [83-87], as well as tumor grade $[88,89]$, have also been described. In particular the two most discriminating texture parameters for differentiating luminal A and luminal B subtypes proved to be sum entropy and sum variance $(p=0.003)$ with AUCs of 0.828 for sum entropy ( $p=0.004), 0.833$ for sum variance $(p=0.003)$, and 0.878 for the model combining sum entropy and sum variance texture features $(p=0.001)$. The sum entropy and sum variance showed a positive correlation with a higher Ki-67 index [83].

Finally, in another study [89], a radiomic model was developed to predict the Ki-67 proliferation index in patients with invasive ductal breast cancer by preoperative magnetic resonance imaging (MRI).

In this study, quantitative imaging features $(n=1029)$ were extracted from ADC maps and 11 features were selected to build the model that showed areas under ROC values (AUC) of $0.75 \pm 0.08$, accuracy of 0.71 in the training set and $0.72,0.70$ in the test set.

In conclusion, in breast cancer, despite the fact that no meta-analyses investigating the overall impact of radiomics have been published, the same pitfalls of this method still exist, with a limited reliability of texture parameters and mainly mono-institutional studies published. At the same time, two observational prospective studies are under development, respectively, to validate metastatic risk based on radiomic features following primary therapy and to assess the performance of CT-based radiomics in evaluating the response and predicting the pCR of metastatic lymph nodes after neoadjuvant therapy (see Table 1).

\section{Texture Analysis and Prognosis-Focus on Gastric Cancer}

Despite the fact that stomach cancer is one of the "big killers" with about 1,000,000 new cases per year, and the third place for mortality among cancer patients [25], there are not many studies of radiomics approaches in this field.

The main topics of radiomics research in this disease deal with differential diagnosis, prognosis assessment and response evaluation. Following the aim of the review, we will focus on prognosis assessment and response evaluation. 
Several studies have been performed on the staging of gastric cancer, in order to evaluate gastric wall infiltration in the distinction between T2 and T3/4 lesions 4 or serosal infiltration for the discrimination between T3 and T4a lesions [106].

Lymph node involvement is one of the parameters with the greatest impact on clinical decisions and patient survival. Therefore, several retrospective studies aim at the creation and validation of models or algorithms that are able to predict the degree of lymph node involvement in the preoperative phase [107-115].

Jiang et al., on 1689 patients, developed a "radiomics signature" that significantly correlates with lymph node metastatic involvement [114]; other researchers have used machine learning [107] or deep learning [109] algorithms, retrospectively analyzing large cohorts of patients for the detection of lymph node metastases.

Many studies have focused on the role that radiomics may have in guiding the therapeutic choice in patients with stomach cancer [116] and therefore in risk stratification and response evaluation before and after medical or surgical treatment. [117-122].

Jing-Wen et al. used a deep learning software for semi-automated segmentation and developed a CT-radiomic approach to predict response to chemotherapy in patients with advanced adenocarcinoma [123].

Jiang et al. conducted a study on 1591 patients by developing radiomics signatures that can predict survival and response to chemotherapy [124].

Li-Whuchao et al. studied the value of TA features in predicting survival after radical surgery [125].

Another group developed a computational approach by integrating large-scale imaging factors, especially radiomic features at contrast-enhanced computed tomography, to predict AHS (adverse histopathological status) and clinical outcomes of patients with GC [126].

Zhang L. et al. [127] developed a radiomic model that is able to distinguish between advanced and non-advanced GIST by retrospectively analyzing 366 patients with suspected GIST.

Zhou et al., instead, studied PET/CT features contributing to prognosis prediction in primary gastric diffuse large B-cell lymphoma (PG-DLBCL) patients [128].

Other investigators have used a D-TA approach to predict the response to neoadjuvant chemotherapy in resectable locally advanced gastric cancer and found that the TA parameter GLCM-contrast was able to predict complete pathologic response with an AUC of 0.763 [129]. Finally, innovative approaches have used radiomics for a non-invasive assessment of the immune microenvironment, correlating the TA features with the Treg cell infiltration or the HER2 expression [130,131].

In conclusion, the development of radiomic models have been shown to have a good predictive performance of response to neoadjuvant chemotherapy.

In particular in one study [118], the rad_score (in the validation cohort) demonstrated a good predicting performance in treatment response to the neoadjuvant chemotherapy (AUC $[95 \% \mathrm{CI}]=0.82[0.67,0.98])$, which was better than the clinical score (based on pre-operative clinical variables)

In another study [117] otherwise a radiomics-based model that incorporated radiomic signature, serum CA72-4, and CT reported lymph node status showed good calibration and discrimination in the training cohort [AUC, 0.92; 95\% confidence interval (CI), [0.89-0.95] and the validation cohort (AUC 0.86; 95\% CI, 0.81-0.91).

Another study [119], instead, developed a radiomic signature using Support Vector Machine (SVM)-based methods that was shown to be an independent predictor of DFS and response to therapy.

Finally, several studies have focused on the possibility of predicting LNM in gastric cancer. The analyzed nomogram composed of radiomic scores showed, in all studies, excellent discrimination in the training and test cohorts with AUC ranging from 0.824 to 0.886 and 0.764 to 0.8456 , respectively [107-113]. 
Furthermore, these models when supplemented with clinicopathological information improved their predictive ability.

In conclusion, in gastric cancer, no meta-analyses investigating the overall impact of radiomics have been published and the same pitfalls of this method still exist, as reported above. Prospective observational studies are yet to be designed; therefore, in the future, several efforts must be made for the clinical management of this disease.

\section{Texture Analysis and Prognosis-Focus on Liver Cancer}

Hepatic lesions are extremely frequent in oncology. Liver is one of the main sites of metastasis [25] and hepatocellular carcinoma (HCC) is the most common primary tumor, representing the second leading cause of death in oncological patients and the first in patients affected by cirrhosis [25,132]. In recent years, many studies have been looking for possible applications of radiomics in the study of hepatic lesions [133-136]. Nowadays, many applications have been consolidated: from early diagnosis to posttreatment evaluation and prognosis predictions [137]. Following the aim of the review, we will focus on response evaluation and prognosis correlation in both primary and metastatic hepatic cancers.

In the setting of primary hepatic cancers, several studies have been published in the field of radiomics. In one work, a radiomic model, based on CT, was used to predict the risk of recurrence in patients with early stage HC [138]. In a further study, a combined radiomic model based on MRI was designed to predict the 5-year survival of patients with HCC. The study showed that AFP, ferritin, and CEA in preoperative, macrovascular invasion, tumor size, sex, and some radiomic features, such as correlation, inverse difference moment, cluster prominence, uniformity, and GLCM energy were independently associated with the postoperative OS of patients with primary liver cancer. Therefore, these characteristics can be considered as potential imaging biomarkers for the postoperative OS of primary liver cancer [139].

Another paper investigated and integrated radiomic features with preoperative AFP and AST values in order to stratify HCC patients into risk groups prior to surgery and thus guide treatment decisions [140].

Most works investigating the potential of radiomics as a prognostic factor analyze features extracted exclusively from the intratumoural portion. On the other hand, Zhang et al. tested a radiomic model to assess the survival of patients with hepatocarcinoma after surgery. In this case, three different ROIs were placed: in the lesion, in the penumbra zone (defined as the area of liver parenchyma surrounding the lesion to a thickness of $1 \mathrm{~cm}$ ) and in the context of healthy liver parenchyma. Changes in radiomic features from the liver parenchyma have been shown to be predictive of patient survival and may provide prognostic information regarding recurrence and metastatic potential; radiomic features involving several regions, therefore, have greater prognostic power than a single lesion assessment [141]. Song et al. also performed a retrospective study, in which radiomic features, based on contrast-enhanced MRI extracted from both the intra- and peri-tumor area, were analyzed. The aim of the study was to evaluate recurrence-free survival in patients undergoing transarterial chemoembolization (TACE). The combined model (combining radiomic and clinic-radiological characteristics) showed the best performance for the assessment of relapse-free survival in patients with HCC after TACE. It was possible to divide patients into two different subgroups, high and low risk of relapse [142]. Notably, by employing CEUS-based deep learning radiomics models, Ma et al. attempted to predict early HCC recurrence after ablation and stratifying patients into subgroups at high and low risk of late recurrence [143].

Conversely, the most common hepatic lesions are not primaries, but metastases, which are 18-40 times more frequent than primary tumors [144]. Out of necessity, therefore, several radiomics studies over the years have focused on hepatic secondarisms. Taghavi et al. attempted to predict the presence of metachronous liver metastases from colorectal cancer by studying microvascular changes in healthy liver parenchyma using a radiomic 
model based on machine learning. It was demonstrated that the combined model (AUC $95 \%$ ) was better able to predict the development of secondarisms in the 24 months after diagnosis, compared with the clinical model (AUC 71\%) and the radiomic model (AUC $86 \%$ ) [145]. A further study investigated the predictive value of radiomics on the presence of synchronous liver metastases in CRC patients. Classical imaging techniques, such as CT and MRI with mdc, can in fact detect the presence of liver lesions, but they do not always lead to appropriate accuracy and sensitivity [146]. A combined predictive model and normogram was constructed using radiomic features, CEA, and CA19-9 levels [147]. It has also been shown that radiomic characteristics can predict treatment efficacy in patients with hepatic secondarisms [134]. In recent years, two papers have been focused on this. Ravanelli et al. used contrast-enhanced CT to extract radiomic features and showed that texture is able to predict the response to Bevacizumab, and it was the best predictor of both overall survival and disease-free survival in patients with liver metastases from unresectable colorectal cancer. In particular, it has been observed that the uniformity of lesions, which is strictly dependent on angiogenesis, correlates with a worse response to treatment [148]. Nakanishi et al. developed a model to predict the response of liver metastases to first-line oxaliplatin-based chemotherapy in patients with CRC using radiomic features extracted from pretreatment CT scans [149].

However, it must be considered that the quantification of radiomic features can be sensitive to several technical factors, such as CT acquisition parameters (peak X-ray tube voltage and current, slice thickness) and reconstruction parameters. A recent study confirmed the poor technical reproducibility of radiomic models based on CT images in patients with early HCC recurrence [150].

To conclude, in liver cancer, two meta-analyses have been published recently, both claiming that analyzed data are sparse and heterogeneous [134,151].

In conclusion, in liver cancer, two meta-analyses have been recently published, both concluding that analyzed data are sparse and heterogeneous [134,151]; in particular, Fiz et al. [134] included 32 studies in their review and found that entropy and homogeneity were the radiomic features with the strongest clinical impact. Higher entropy at baseline and lower LM homogeneity were associated with better survival and higher chemotherapy response rates. Decreased entropy and increased homogeneity after chemotherapy were correlated with radiological tumor response. Entropy and homogeneity were also highly predictive of the degree of tumor regression. Finally, it was shown that texture analyses could differentiate LM from other liver tumors.

In another meta-analysis Beckers et al., [151] analyzed 16 studies showing that ADC (apparent diffusion coefficient, on MRI) is the most promising predictor of response and survival, whereas in studies related to $\mathrm{CT}$, texture features show promising results. In FDG-PET(-CT), the results were rather ambiguous.

There are still many limitations, such as small sample size, retrospective design, lack of validation datasets, and unavailability of univocal cut-off values of radiomic features. Currently, two prospective studies are recruiting patients to compare imaging findings, genomics, and pathology parameters.

\section{Texture Analysis and Prognosis-Focus on Rectal Cancer}

Rectal cancer (RC) accounts for one third of all colorectal cancers and is one of the leading causes of cancer death in the Western world in both sexes [25,152-154]. IN actual fact, neoadjuvant chemo-radiotherapy (nCRT) followed by total meso-rectal excision (TME) is the gold-standard treatment for patients with locally advanced rectal cancer (LARC) [155], as it increases PFS and allows, at the same time, a less invasive surgery with a lower frequency of complications, albeit its effects on overall survival (OS) is still to be proven [156,157]; in a significant percentage of patients, nCRT led to a pathological complete response (pCR) [158-160], a concept that has led to new conservative strategies ("watch-and-wait" or local excision) that could be attempted in order to avoid invasive 
surgery with the risk of major complications and a possible worsening of the quality of life [161].

Given these premises, the main clinical challenge is to preoperatively diagnose $\mathrm{pCR}$ in patients with LARC after nCRT. Although magnetic resonance imaging (MRI) is the standard imaging technique for local staging and re-evaluation after nCRT in RC [162-165], its clinical utility in predicting pCR after nCRT is still uncertain. In this scenario, radiomics has emerged as a promising tool and several studies have shown promising results in the prediction and early assessment of response to chemotherapy using MRI [166-168]. Following the aim of the review, we will focus on studies investigating the prediction of response and the prognosis of LARC patients.

In particular, studies in the literature have shown that several first-order radiomic features, extracted from T2-weighted (WI) images, are associated with the pCR [169,170].

Horvat et al. [171] indicated that radiomic features extrapolated from post C-RT T2W images could predict pCR. Nie K et al. [172], again, reported the predictive value of pCR based on radiomic features extracted from pre C-RT DWI MRI, with a promising AUC of 0.79. Chen et al. [173] demonstrated that MRI-based radiomics is a sophisticated and non-invasive tool to accurately distinguish recurrent (LR) lesions from (non-recurrent) lesions at the site of anastomosis and, in particular, the combination of multiple sequences in MRI significantly improved its performance. In this study, the ROC curve of modelcombination indicated an AUC of 0.864 (validation set), with sensitivity and specificity of $81-82 \%$ and $75-86 \%$, respectively, suggesting that model-combination may provide better discrimination performance than individual models $(p>0.05)$. Interestingly, extracting and combining quantitative features from multiple MRI sequences significantly improves model performance, making it more effective.

During C-RT, intra-tumor heterogeneity is dynamic, therefore, radiomic features extracted from single-sequence images (i.e., pre or post C-RT) may overlook tumor change during treatment and have inherent limitations [174]. Therefore, delta-radiomics, which is defined as the change in quantitative radiomic characteristics in a series of longitudinal images in order to detect information about changes in intra-tumor heterogeneity and to adapt therapy, represents a new frontier in radiomics. Wan et al. [175] developed and evaluated the performance of the delta-radiomic model, based on pre- and post C-RT MRI percentage changes, for $\mathrm{PCR}$ prediction after nCRT. The developed combined model (using T2WI and DWI) provided the best performance for $\mathrm{pCR}$ prediction with AUCs of 0.91 and 0.91 in the training and validation sets, which were superior to those of the mrTRG and delta-radiomic models developed using only T2WI or DWI. Instead, Boldrini et al. [21] investigated the predictive power of delta-radiomic features extrapolated from hybrid $0.35 \mathrm{~T}$ magnetic resonance (MR)-guided radiotherapy (MRgRT) in LARC patients undergoing pre-nCRT. This study showed that the variation in three delta features, such as energy, grey level non-uniformity and least axis length, showed a statistically significant association ( $p$-value $<0.05$ ), demonstrating a correlation with the $\mathrm{CCR}$.

Other authors have investigated additional techniques of imaging, such as ultrasound (US), which was used to develop a radiomic model based on the machine learning of the US to pre-operatively predict tumor deposits (TD) [176]. Studies have confirmed that TDpositive patients have more aggressive tumors, with poorer disease-free survival (hazard ratio, HR, 1.7 to 2.0) and poorer overall survival (HR, 2.2 to 2.9) [177]. Yuan et al. [178], on the other hand, used a machine learning technique to build radiomics models by extracting radiomic features on non-contrast $\mathrm{CT}$ images, and predict the response to treatment. Bibault et al. [179] reported $80 \%$ accuracy in predicting a complete response in LARC with nCRT using radiomic features extracted from a post-contrast $\mathrm{CT}$ through a deep neural network algorithm. Chee et al. showed that first-order features extracted from CT were associated with response to CRT [180].

Other investigators have investigated the role of TA in the prognosis, with the prediction of distant metastases (DM). A delta-radiomics approach was used to predict the occurrence of distant metastases by Chiloiro et al. [181], whereas another study [182] validated a 
radiomic model capable of predicting postoperative DM by stratifying patients who might benefit from adjuvant chemotherapy. Liu et al., instead, evaluated the role of pre-nCRT MRI radiomic parameters in predicting synchronous DM in 177 patients with RC with an area under the ROC (AUC) of 0.827 (95\% confidence interval (CI), 0.6963-0.9580) [183]. Nardone et al. [184] found a correlation between pre-nCRT MRI texture analysis and early disease progression in 49 patients. In particular, this study showed that patients with a higher GLCM contrast and a lower GLCM correlation showed recurrence and/or DM within three months after radical surgery.

In conclusion, the applications of artificial intelligence in the field of rectal cancer oncology management are varied and very promising, as it could contribute to increasingly personalize patient management and improve survival.

Two meta-analyses have been recently published in the field of colorectal cancer $[185,186]$, with heterogeneous results regarding radiomics methods and included features. At the same time, several studies were able to predict response with good performance. In particular, a recent meta-analysis [186] showed that, at present, few studies have investigated the predictive value of first order radiomic features and that, among them, kurtosis was found to be a significant predictor of treatment response, achieving the highest AUC 0.91 in predicting pCR; for second order radiomic features, more disparate results were obtained with AUCs ranging from 0.54 to 0.99 .

Currently, several observational prospective studies are under development with the aim to predict response to neoadjuvant therapies and/or predict cancer prognosis (see Table 1).

\section{Texture Analysis and Prognosis-Focus on other Cancers}

TA has been applied in several settings in many other cancer diseases, such as bladder and prostate cancers, brain cancer (both primary or metastastic), sarcoma, kidney cancer, Hodgkin and non-Hodgkin lymphoma, gynaecological cancer, and head and neck cancers.

These heterogeneous diseases are usually managed with a combination of different strategies, such as surgery, radiotherapy, chemotherapy and immunotherapy. In this context, TA has been applied for different purposes, such as the prediction of prognosis, the correlation with grading or other histological characteristics, and differential diagnosis both in the diagnosis and in the response to therapies.

Many meta-analyses have recently been published in this heterogeneous context and, in this paragraph, we will summarize their results in the above-mentioned diseases.

Kozikowski et al. investigated the role of TA in the prediction of muscle-invasive bladder cancer and analyzed eight studies with a total of 860 included patients [187]. The authors found several differences in approaches, although TA models were found to be relatively homogeneous in diagnostic accuracy.

Stanzione et al. performed a meta-analysis of TA approaches in prostate cancer and assessed the 73 included studies with a radiomic quality score (RQS) [188,189]. The authors concluded that prostate TA still lacks the quality required to allow for its introduction in clinical practice, due to the lack of feature robustness testing strategies and external validation datasets. On the contrary, Castaldo et al. analyzed radiomic and genomic machine learning methods in the detection of prostate cancer [190] and found that, despite the above limitations, the performance was considered satisfactory for several studies investigating multiparametric magnetic resonance imaging and urine biomarkers.

In brain cancer, several TA studies have been published in the last decade, mainly in the field of grading prediction of glioma and meningioma, prognosis prediction and differential diagnosis of progression versus radionecrosis in radiotherapy-treated patients. Tabatabaei et al. and Ugga et al. recently performed similar meta-analyses for the prediction of grading in glioma and meningioma, respectively [191,192]. The authors both concluded that future studies with adequate standardization and higher methodological quality are required, prior to the introduction of TA in clinical practice for this purpose. The same 
conclusion was reached by Kim et al. in the setting of TA prediction of true progression versus radionecrosis after radiotherapy for brain metastases [193].

Crombè et al. explored the potential of TA in different sarcoma diseases [194] and included 52 studies. They concluded that, despite the promising results, further efforts are needed to make sarcoma radiomics studies reproducible with an acceptable level of evidence. In this context, Gitto et al. investigated the reproducibility and validation strategies, and found a huge variation among different studies, thus mining the introduction of TA in the clinical setting [195].

Different TA approaches have been used in the setting of renal cancer, mainly with the aim of differential diagnosis of histological subtypes in the prediction of therapy response and survival. Ursprung et al. calculated an odds ratio of 6.24 (95\% CI 4.27-9.12; $p<0.001)$ for the differentiation of angiomyolipoma without visible fat from renal cell carcinoma [196]. Mühlbauer et al., similarly, concluded that this approach seems promising in the differential diagnosis of histological subtypes, but shared data and open science must aid in improving reproducibility of future studies [197].

Frood et al. investigated the role of baseline nuclear medicine imaging in the prediction of treatment outcome in Hodgkin and diffuse large B cell lymphoma [198] and concluded that further work in harmonization, segmentation and performance cut-off is required to develop robust methodologies that are amenable for clinical utility.

TA approaches have been tested in gynaecological cancers with different aims, such as the prediction of prognosis of ovarian cancer patients [199] or the radiological preoperative assessment of patients with endometrial carcinoma [200]. There is currently insufficient evidence on the benefit of TA approaches in this context, despite this field being promising for future clinical practice.

TA approaches have also been used in the field of head and neck cancers, mainly with the aim of predicting radiotherapy side effects or to predict prognosis. Carbonara et al. included 8 papers in their meta-analysis, presenting data on parotid glands, cochlea, masticatory muscles, and white brain matter after head and neck radiotherapy [201]. Unfortunately, the RQS of presented studies was low and further studies are needed in the future to validate the TA in this setting. Creff et al. and Guha et al. analyzed the potential role of TA in the prediction of prognosis [202,203] and both authors found significant heterogeneity among the included studies, with the lack of robust external validation studies on the reproducibility and accuracy of TA.

\section{Conclusions}

All the above-mentioned studies have shown interesting results or texture analysis approaches in different diseases. At the same time, there are still several pitfalls to resolve before TA can be successfully applied in the clinical management of cancer patients.

The standardization of both image acquisition and feature extractions, as well as data sharing and the distrust of the clinicians in the black box approach represent the major problems to solve in the future.

The ideal solution for standardization is to define the methods in dedicated prospective trials. It is necessary to underline the fact that, despite an impressive number of retrospective published papers, the number of prospective trials investigating radiomics in cancer therapy is inexplicably low.

Additionally, several efforts should be made in the development of high-number and high-quality shared databases in the future. These datasets require joint efforts by both companies and institutions, such as Cancer Learning Intelligence Network for Quality and Flatiron Health, the Cancer Imaging Archive.

Radiomic parameters are very difficult to describe and to refer to known clinical variables, thus TA looks like a black box to the Clinicians. In this regard, further work should be performed to correlate radiomics to underlying clinical and molecular connotations, with approaches such as radiogenomics. 
At the same time, the use of structured reports in radiology in the future could be integrated with radiomic data correlated to prognosis or response to therapies, in order to facilitate the clinicians to understand the TA approach [204-206].

By setting up the ambitious goal of addressing these challenges, radiomics can become a clinical reality in the next few years and a higher number of prospective trials can be designed and conducted in the near future.

Author Contributions: Conceptualization, A.R., V.N., S.C., R.G. (Roberto Grassi); methodology, V.N., G.G., M.P.B., R.G. (Roberta Grassi), F.S., M.D.C., data curation, V.N., G.G., M.P.B., R.G. (Roberta Grassi), F.S., M.D.C.; writing—original draft preparation, V.N., G.G., M.P.B., R.G. (Roberto Grassi), F.S., M.D.C., R.G. (Roberta Grassi); writing-review and editing: A.R., V.N., S.C., G.G. All authors have read and agreed to the published version of the manuscript.

Funding: This research was funded by SIRM foundation.

Conflicts of Interest: The authors declare no conflict of interest.

\section{References}

1. Schwartz, L.H.; Litière, S.; de Vries, E.; Ford, R.; Gwyther, S.; Mandrekar, S.; Shankar, L.; Bogaerts, J.; Chen, A.; Dancey, J.; et al. RECIST 1.1-Update and clarification: From the RECIST committee. Eur. J. Cancer 2016, 62, 132-137. [CrossRef]

2. Seymour, L.; Bogaerts, J.; Perrone, A.; Ford, R.; Schwartz, L.H.; Mandrekar, S.; Lin, N.U.; Litiere, S.; Dancey, J.; Chen, A.; et al. iRECIST: Guidelines for response criteria for use in trials testing immunotherapeutics. Lancet Oncol. 2017, 18, e143-e152. [CrossRef]

3. Grassi, R.; Fusco, R.; Belfiore, M.P.; Montanelli, A.; Patelli, G.; Urraro, F.; Petrillo, A.; Granata, V.; Sacco, P.; Mazzei, M.A.; et al. Coronavirus Disease 2019 (COVID-19) in Italy: Features on Chest Computed Tomography using a structured report system. Sci. Rep. 2020, 10, 1-11. [CrossRef]

4. Rocha, D.M.; Brasil, L.M.; Lamas, J.M.; Luz, G.V.S.; Bacelar, S.S. Evidence of the benefits, advantages and potentialities of the structured radiological report: An integrative review. Artif. Intell. Med. 2020, 102, 101770. [CrossRef] [PubMed]

5. Neri, E.; Miele, V.; Coppola, F.; Grassi, R. Use of CT and artificial intelligence in suspected or COVID-19 positive patients: Statement of the Italian Society of Medical and Interventional Radiology. Radiol. Med. 2020, 125, 505-508. [CrossRef]

6. Avanzo, M.; Stancanello, J.; El Naqa, I. Beyond imaging: The promise of radiomics. Phys. Med. Eur. J. Med. Phys. 2017, 38, 122-139. [CrossRef]

7. Ganeshan, B.; Miles, K.A. Quantifying tumour heterogeneity with CT. Cancer Imaging Off. Publ. Int. Cancer Imaging Soc. 2013, 13, 140-149. [CrossRef]

8. Gitto, S.; Grassi, G.; De Angelis, C.; Monaco, C.G.; Sdao, S.; Sardanelli, F.; Sconfienza, L.M.; Mauri, G. A computer-aided diagnosis system for the assessment and characterization of low-to-high suspicion thyroid nodules on ultrasound. Radiol. Med. 2019, 124, 118-125. [CrossRef]

9. Vidiri, A.; Minosse, S.; Piludu, F.; Pellini, R.; Cristalli, G.; Kayal, R.; Carlino, G.; Renzi, D.; Covello, R.; Marzi, S. Cervical lymphadenopathy: Can the histogram analysis of apparent diffusion coefficient help to differentiate between lymphoma and squamous cell carcinoma in patients with unknown clinical primary tumor? Radiol. Med. 2019, 124, 19-26. [CrossRef]

10. Kirienko, M.; Ninatti, G. Computed tomography (CT)-derived radiomic features differentiate prevascular mediastinum masses as thymic neoplasms versus lymphomas. Radiol. Med. 2020, 125, 951-960. [CrossRef] [PubMed]

11. Lian, S.; Zhang, C.; Chi, J.; Huang, Y.; Shi, F.; Xie, C. Differentiation between nasopharyngeal carcinoma and lymphoma at the primary site using whole-tumor histogram analysis of apparent diffusion coefficient maps. Radiol. Med. 2020, 125, 647-653. [CrossRef] [PubMed]

12. Nazari, M.; Shiri, I.; Hajianfar, G.; Oveisi, N.; Abdollahi, H.; Deevband, M.R.; Oveisi, M.; Zaidi, H. Noninvasive Fuhrman grading of clear cell renal cell carcinoma using computed tomography radiomic features and machine learning. Radiol. Med. 2020, 125, 754-762. [CrossRef] [PubMed]

13. Coppola, F.; Faggioni, L.; Regge, D.; Giovagnoni, A.; Golfieri, R.; Bibbolino, C.; Miele, V.; Neri, E.; Grassi, R. Artificial intelligence: Radiologists' expectations and opinions gleaned from a nationwide online survey. Radiol. Med. 2021, 126, 63-71. [CrossRef]

14. Grassi, R.; Miele, V. Artificial intelligence: A challenge for third millennium radiologist. Radiol. Med. 2019, 124, 241-242. [CrossRef]

15. Neri, E.; Coppola, F.; Miele, V.; Bibbolino, C.; Grassi, R. Artificial intelligence: Who is responsible for the diagnosis? Radiol. Med. 2020, 125, 517-521. [CrossRef]

16. Rossi, F.; Bignotti, B.; Bianchi, L.; Picasso, R.; Martinoli, C.; Tagliafico, A.S. Radiomics of peripheral nerves MRI in mild carpal and cubital tunnel syndrome. Radiol. Med. 2020, 125, 197-203. [CrossRef]

17. Nardone, V.; Tini, P.; Carbone, S.F.; Grassi, A.; Biondi, M.; Sebaste, L.; Carfagno, T.; Vanzi, E.; De Otto, G.; Battaglia, G.; et al. Bone texture analysis using CT-simulation scans to individuate risk parameters for radiation-induced insufficiency fractures. Osteoporos. Int. 2017, 28, 1915-1923. [CrossRef] 
18. Nardone, V.; Tini, P.; Croci, S.; Carbone, S.F.; Sebaste, L.; Carfagno, T.; Battaglia, G.; Pastina, P.; Rubino, G.; Mazzei, M.A.; et al. 3D bone texture analysis as a potential predictor of radiation-induced insufficiency fractures. Quant. Imaging Med. Surg. 2018, 8, 14-24. [CrossRef] [PubMed]

19. Belfiore, M.P.; Urraro, F.; Grassi, R.; Giacobbe, G.; Patelli, G.; Cappabianca, S.; Reginelli, A. Artificial intelligence to codify lung CT in Covid-19 patients. Radiol. Med. 2020, 125, 500-504. [CrossRef]

20. van Assen, M.; Muscogiuri, G.; Caruso, D.; Lee, S.J.; Laghi, A.; De Cecco, C.N. Artificial intelligence in cardiac radiology. Radiol. Med. 2020, 125, 1186-1199. [CrossRef] [PubMed]

21. Boldrini, L.; Cusumano, D.; Chiloiro, G.; Casa, C.; Masciocchi, C.; Lenkowicz, J.; Cellini, F.; Dinapoli, N.; Azario, L.; Teodoli, S.; et al. Delta radiomics for rectal cancer response prediction with hybrid $0.35 \mathrm{~T}$ magnetic resonance-guided radiotherapy (MRgRT): A hypothesis-generating study for an innovative personalized medicine approach. Radiol. Med. 2019, 124, 145-153. [CrossRef] [PubMed]

22. Jeon, S.H.; Song, C.; Chie, E.K.; Kim, B.; Kim, Y.H.; Chang, W.; Lee, Y.J.; Chung, J.H.; Chung, J.B.; Lee, K.W.; et al. Delta-radiomics signature predicts treatment outcomes after preoperative chemoradiotherapy and surgery in rectal cancer. Radiat. Oncol. 2019, 14, 43. [CrossRef]

23. Mazzei, M.A.; Nardone, V.; Di Giacomo, L.; Bagnacci, G.; Gentili, F.; Tini, P.; Marrelli, D.; Volterrani, L. The role of delta radiomics in gastric cancer. Quant. Imaging Med. Surg. 2018, 8, 719-721. [CrossRef]

24. Nardone, V.; Reginelli, A.; Guida, C.; Belfiore, M.P.; Biondi, M.; Mormile, M.; Banci Buonamici, F.; Di Giorgio, E.; Spadafora, M.; Tini, P.; et al. Delta-radiomics increases multicentre reproducibility: A phantom study. Med. Oncol. 2020, 37, 38. [CrossRef]

25. Siegel, R.L.; Miller, K.D.; Jemal, A. Cancer Statistics, 2017. CA Cancer J. Clin. 2017, 67, 7-30. [CrossRef]

26. Nardone, V.; Pastina, P.; Giannicola, R.; Agostino, R.; Croci, S.; Tini, P.; Pirtoli, L.; Giordano, A.; Tagliaferri, P.; Correale, P. How to Increase the Efficacy of Immunotherapy in NSCLC and HNSCC: Role of Radiation Therapy, Chemotherapy, and Other Strategies. Front. Immunol. 2018, 9, 2941. [CrossRef]

27. Tini, P.; Nardone, V.; Pastina, P.; Pirtoli, L.; Correale, P.; Giordano, A. The effects of radiotherapy on the survival of patients with unresectable non-small cell lung cancer. Expert Rev. Anticancer 2018, 18, 593-602. [CrossRef]

28. Machado Medeiros, T.; Altmayer, S.; Watte, G.; Zanon, M.; Basso Dias, A.; Henz Concatto, N.; Hoefel Paes, J.; Mattiello, R.; de Souza Santos, F.; Mohammed, T.L.; et al. 18F-FDG PET/CT and whole-body MRI diagnostic performance in M staging for non-small cell lung cancer: A systematic review and meta-analysis. Eur. Radiol. 2020, 30, 3641-3649. [CrossRef] [PubMed]

29. Pak, K.; Park, S.; Cheon, G.J.; Kang, K.W.; Kim, I.J.; Lee, D.S.; Kim, E.E.; Chung, J.K. Update on nodal staging in non-small cell lung cancer with integrated positron emission tomography/computed tomography: A meta-analysis. Ann. Nucl. Med. 2015, 29, 409-419. [CrossRef] [PubMed]

30. Zhang, Y.; Ni, J.; Wei, K.; Tian, J.; Sun, S. CT, MRI, and F-18 FDG PET for the detection of non-small-cell lung cancer (NSCLC): A protocol for a network meta-analysis of diagnostic test accuracy. Medicine 2018, 97, e12387. [CrossRef]

31. Arrigoni, F.; Bruno, F.; Zugaro, L.; Natella, R.; Cappabianca, S.; Russo, U.; Papapietro, V.R.; Splendiani, A.; Di Cesare, E.; Masciocchi, C.; et al. Developments in the management of bone metastases with interventional radiology. Acta Biomed. 2018, 89, 166-174. [CrossRef]

32. Reginelli, A.; Silvestro, G.; Fontanella, G.; Sangiovanni, A.; Conte, M.; Nuzzo, I.; Calvanese, M.; Traettino, M.; Ferraioli, P.; Grassi, R.; et al. Validation of DWI in assessment of radiotreated bone metastases in elderly patients. Int. J. Surg. 2016, 33 (Suppl. 1), S148-S153. [CrossRef]

33. Alessio, N.; Capasso, S.; Di Bernardo, G.; Cappabianca, S.; Casale, F.; Calarco, A.; Cipollaro, M.; Peluso, G.; Galderisi, U. Mesenchymal stromal cells having inactivated RB1 survive following low irradiation and accumulate damaged DNA: Hints for side effects following radiotherapy. Cell Cycle 2017, 16, 251-258. [CrossRef]

34. Nardone, V.; Tini, P.; Pastina, P.; Botta, C.; Reginelli, A.; Carbone, S.F.; Giannicola, R.; Calabrese, G.; Tebala, C.; Guida, C.; et al. Radiomics predicts survival of patients with advanced non-small cell lung cancer undergoing PD-1 blockade using Nivolumab. Oncol. Lett. 2020, 19, 1559-1566. [CrossRef] [PubMed]

35. Sollini, M.; Cozzi, L.; Antunovic, L.; Chiti, A. PET Radiomics in NSCLC: State of the art and a proposal for harmonization of methodology. Sci. Rep. 2017, 7, 358. [CrossRef] [PubMed]

36. Rabbani, M.; Kanevsky, J.; Kafi, K.; Chandelier, F.; Giles, F.J. Role of artificial intelligence in the care of patients with nonsmall cell lung cancer. Eur. J. Clin. Investig. 2018, 48, e12901. [CrossRef]

37. Wong, C.W.; Chaudhry, A. Radiogenomics of lung cancer. J. Thorac. Dis. 2020, 12, 5104-5109. [CrossRef]

38. Shi, L.; He, Y.; Yuan, Z.; Benedict, S.; Valicenti, R.; Qiu, J.; Rong, Y. Radiomics for Response and Outcome Assessment for Non-Small Cell Lung Cancer. Technol. Cancer Res. Treat. 2018, 17, 1533033818782788. [CrossRef] [PubMed]

39. Ninatti, G.; Kirienko, M.; Neri, E.; Sollini, M.; Chiti, A. Imaging-Based Prediction of Molecular Therapy Targets in NSCLC by Radiogenomics and AI Approaches: A Systematic Review. Diagnostics 2020, 10, 359. [CrossRef] [PubMed]

40. Reginelli, A.; Di Grezia, G.; Izzo, A.; D’Andrea, A.; Gatta, G.; Cappabianca, S.; Squillaci, E.; Grassi, R. Imaging of adrenal incidentaloma: Our experience. Int. J. Surg. 2014, 12 (Suppl. 1), S126-S131. [CrossRef]

41. Sun, J.; Hu, D.; Shen, Y.; Yang, H.; Chen, C.; Yin, J.; Peng, Y. Improving image quality with model-based iterative reconstruction algorithm for chest CT in children with reduced contrast concentration. Radiol. Med. 2019, 124, 595-601. [CrossRef] 
42. Cook, G.J.; Yip, C.; Siddique, M.; Goh, V.; Chicklore, S.; Roy, A.; Marsden, P.; Ahmad, S.; Landau, D. Are pretreatment 18F-FDG PET tumor textural features in non-small cell lung cancer associated with response and survival after chemoradiotherapy? $J$. Nucl. Med. 2013, 54, 19-26. [CrossRef]

43. Dong, X.; Sun, X.; Sun, L.; Maxim, P.G.; Xing, L.; Huang, Y.; Li, W.; Wan, H.; Zhao, X.; Xing, L.; et al. Early Change in Metabolic Tumor Heterogeneity during Chemoradiotherapy and Its Prognostic Value for Patients with Locally Advanced Non-Small Cell Lung Cancer. PLoS ONE 2016, 11, e0157836. [CrossRef]

44. Coroller, T.P.; Agrawal, V.; Narayan, V.; Hou, Y.; Grossmann, P.; Lee, S.W.; Mak, R.H.; Aerts, H.J. Radiomic phenotype features predict pathological response in non-small cell lung cancer. Radiother. Oncol. 2016, 119, 480-486. [CrossRef]

45. Coroller, T.P.; Agrawal, V.; Huynh, E.; Narayan, V.; Lee, S.W.; Mak, R.H.; Aerts, H. Radiomic-Based Pathological Response Prediction from Primary Tumors and Lymph Nodes in NSCLC. J. Thorac. Oncol. 2017, 12, 467-476. [CrossRef]

46. Cook, G.J.; O’Brien, M.E.; Siddique, M.; Chicklore, S.; Loi, H.Y.; Sharma, B.; Punwani, R.; Bassett, P.; Goh, V.; Chua, S. Non-Small Cell Lung Cancer Treated with Erlotinib: Heterogeneity of (18)F-FDG Uptake at PET-Association with Treatment Response and Prognosis. Radiology 2015, 276, 883-893. [CrossRef]

47. Kang, S.R.; Song, H.C.; Byun, B.H.; Oh, J.R.; Kim, H.S.; Hong, S.P.; Kwon, S.Y.; Chong, A.; Kim, J.; Cho, S.G.; et al. Intratumoral Metabolic Heterogeneity for Prediction of Disease Progression After Concurrent Chemoradiotherapy in Patients with Inoperable Stage III Non-Small-Cell Lung Cancer. Nucl. Med. Mol. Imaging 2014, 48, 16-25. [CrossRef] [PubMed]

48. Lovinfosse, P.; Janvary, Z.L.; Coucke, P.; Jodogne, S.; Bernard, C.; Hatt, M.; Visvikis, D.; Jansen, N.; Duysinx, B.; Hustinx, R. FDG PET/CT texture analysis for predicting the outcome of lung cancer treated by stereotactic body radiation therapy. Eur. J. Nucl. Med. Mol. Imaging 2016, 43, 1453-1460. [CrossRef] [PubMed]

49. Fave, X.; Zhang, L.; Yang, J. Delta-radiomics features for the prediction of patient outcomes in non-small cell lung cancer. Sci. Rep. 2017, 7, 588. [CrossRef] [PubMed]

50. Fried, D.V.; Tucker, S.L.; Zhou, S.; Liao, Z.; Mawlawi, O.; Ibbott, G.; Court, L.E. Prognostic value and reproducibility of pretreatment CT texture features in stage III non-small cell lung cancer. Int. J. Radiat. Oncol. Biol. Phys. 2014, 90, 834-842. [CrossRef]

51. van Timmeren, J.E.; Leijenaar, R.T.H.; van Elmpt, W.; Reymen, B.; Lambin, P. Feature selection methodology for longitudinal cone-beam CT radiomics. Acta Oncol. 2017, 56, 1537-1543. [CrossRef] [PubMed]

52. Paul, J.; Yang, C.; Wu, H.; Tai, A.; Dalah, E.; Zheng, C.; Johnstone, C.; Kong, F.M.; Gore, E.; Li, X.A. Early Assessment of Treatment Responses During Radiation Therapy for Lung Cancer Using Quantitative Analysis of Daily Computed Tomography. Int. J. Radiat. Oncol. Biol. Phys. 2017, 98, 463-472. [CrossRef] [PubMed]

53. Pyka, T.; Bundschuh, R.A.; Andratschke, N.; Mayer, B.; Specht, H.M.; Papp, L.; Zsótér, N.; Essler, M. Textural features in pre-treatment [F18]-FDG-PET/CT are correlated with risk of local recurrence and disease-specific survival in early stage NSCLC patients receiving primary stereotactic radiation therapy. Radiat. Oncol. 2015, 10, 100. [CrossRef]

54. Mattonen, S.A.; Palma, D.A.; Johnson, C.; Louie, A.V.; Landis, M.; Rodrigues, G.; Chan, I.; Etemad-Rezai, R.; Yeung, T.P.; Senan, S.; et al. Detection of Local Cancer Recurrence After Stereotactic Ablative Radiation Therapy for Lung Cancer: Physician Performance Versus Radiomic Assessment. Int. J. Radiat. Oncol. Biol. Phys. 2016, 94, 1121-1128. [CrossRef]

55. Mattonen, S.A.; Davidzon, G.A.; Bakr, S.; Echegaray, S.; Leung, A.N.C.; Vasanawala, M.; Horng, G.; Napel, S.; Nair, V.S. [18F] FDG Positron Emission Tomography (PET) Tumor and Penumbra Imaging Features Predict Recurrence in Non-Small Cell Lung Cancer. Tomography 2019, 5, 145-153. [CrossRef]

56. Krarup, M.M.K.; Nygård, L.; Vogelius, I.R.; Andersen, F.L.; Cook, G.; Goh, V.; Fischer, B.M. Heterogeneity in tumours: Validating the use of radiomic features on (18)F-FDG PET/CT scans of lung cancer patients as a prognostic tool. Radiother. Oncol. 2020, 144, 72-78. [CrossRef]

57. van Laar, M.; van Amsterdam, W.A.C.; van Lindert, A.S.R.; de Jong, P.A.; Verhoeff, J.J.C. Prognostic factors for overall survival of stage III non-small cell lung cancer patients on computed tomography: A systematic review and meta-analysis. Radiother. Oncol. 2020, 151, 152-175. [CrossRef]

58. Kothari, G.; Korte, J.; Lehrer, E.J.; Zaorsky, N.G.; Lazarakis, S.; Kron, T.; Hardcastle, N.; Siva, S. A systematic review and meta-analysis of the prognostic value of radiomics based models in non-small cell lung cancer treated with curative radiotherapy. Radiother. Oncol. 2021, 155, 188-203. [CrossRef]

59. Ellsworth, R.E.; Decewicz, D.J.; Shriver, C.D.; Ellsworth, D.L. Breast cancer in the personal genomics era. Curr. Genom. 2010, 11, 146-161. [CrossRef] [PubMed]

60. Friedewald, S.M.; Rafferty, E.A.; Rose, S.L.; Durand, M.A.; Plecha, D.M.; Greenberg, J.S.; Hayes, M.K.; Copit, D.S.; Carlson, K.L.; Cink, T.M.; et al. Breast cancer screening using tomosynthesis in combination with digital mammography. JAMA 2014, 311, 2499-2507. [CrossRef] [PubMed]

61. Houssami, N.; Turner, R.M.; Morrow, M. Meta-analysis of pre-operative magnetic resonance imaging (MRI) and surgical treatment for breast cancer. Breast Cancer Res. Treat. 2017, 165, 273-283. [CrossRef]

62. Di Grezia, G.; Somma, F.; Serra, N.; Reginelli, A.; Cappabianca, S.; Grassi, R.; Gatta, G. Reducing Costs of Breast Examination: Ultrasound Performance and Inter-Observer Variability of Expert Radiologists Versus Residents. Cancer Investig. 2016, 34, 355-360. [CrossRef] 
63. Reginelli, A.; Urraro, F.; di Grezia, G.; Napolitano, G.; Maggialetti, N.; Cappabianca, S.; Brunese, L.; Squillaci, E. Conventional ultrasound integrated with elastosonography and B-flow imaging in the diagnosis of thyroid nodular lesions. Int. J. Surg. 2014, 12 (Suppl. 1), S117-S122. [CrossRef] [PubMed]

64. Goldhirsch, A.; Wood, W.C.; Coates, A.S.; Gelber, R.D.; Thurlimann, B.; Senn, H.J. Strategies for subtypes-dealing with the diversity of breast cancer: Highlights of the St. Gallen International Expert Consensus on the Primary Therapy of Early Breast Cancer 2011. Ann. Oncol. 2011, 22, 1736-1747. [CrossRef] [PubMed]

65. Colas, C.; Golmard, L.; de Pauw, A.; Caputo, S.M.; Stoppa-Lyonnet, D. “Decoding hereditary breast cancer" benefits and questions from multigene panel testing. Breast 2019, 45, 29-35. [CrossRef]

66. Reig, B.; Heacock, L.; Geras, K.J.; Moy, L. Machine learning in breast MRI. J. Magn. Reson. Imaging 2020, 52, 998-1018. [CrossRef] [PubMed]

67. Zhang, A.; Song, J.; Ma, Z. Combined dynamic contrast-enhanced magnetic resonance imaging and diffusion-weighted imaging to predict neoadjuvant chemotherapy effect in FIGO stage IB2-IIA2 cervical cancers. Radiol. Med. 2020, 125, 1233-1242. [CrossRef]

68. Filograna, L.; Lenkowicz, J.; Cellini, F.; Dinapoli, N.; Manfrida, S.; Magarelli, N.; Leone, A.; Colosimo, C.; Valentini, V. Identification of the most significant magnetic resonance imaging (MRI) radiomic features in oncological patients with vertebral bone marrow metastatic disease: A feasibility study. Radiol. Med. 2019, 124, 50-57. [CrossRef]

69. Ciolina, M.; Vinci, V.; Villani, L.; Gigli, S.; Saldari, M.; Panici, P.B.; Perniola, G.; Laghi, A.; Catalano, C.; Manganaro, L. Texture analysis versus conventional MRI prognostic factors in predicting tumor response to neoadjuvant chemotherapy in patients with locally advanced cancer of the uterine cervix. Radiol. Med. 2019, 124, 955-964. [CrossRef]

70. Abdollahi, H.; Mofid, B.; Shiri, I.; Razzaghdoust, A.; Saadipoor, A.; Mahdavi, A.; Galandooz, H.M.; Mahdavi, S.R. Machine learning-based radiomic models to predict intensity-modulated radiation therapy response, Gleason score and stage in prostate cancer. Radiol. Med. 2019, 124, 555-567. [CrossRef]

71. Jimenez-Pastor, A.; Alberich-Bayarri, A.; Fos-Guarinos, B.; Garcia-Castro, F.; Garcia-Juan, D.; Glocker, B.; Marti-Bonmati, L. Automated vertebrae localization and identification by decision forests and image-based refinement on real-world CT data. Radiol. Med. 2020, 125, 48-56. [CrossRef]

72. Lee, S.H.; Park, H.; Ko, E.S. Radiomics in Breast Imaging from Techniques to Clinical Applications: A Review. Korean J. Radiol. 2020, 21, 779-792. [CrossRef]

73. Vallières, M.; Freeman, C.R.; Skamene, S.R.; El Naqa, I. A radiomics model from joint FDG-PET and MRI texture features for the prediction of lung metastases in soft-tissue sarcomas of the extremities. Phys. Med. Biol. 2015, 60, 5471-5496. [CrossRef] [PubMed]

74. Maragos, P. Pattern spectrum and multiscale shape representation. IEEE Trans. Pattern Anal. Mach. Intell. 1989, 11, 701-716. [CrossRef]

75. Li, H.; Mendel, K.R. Digital Mammography in Breast Cancer: Additive Value of Radiomics of Breast Parenchyma. Radiology 2019, 291, 15-20. [CrossRef] [PubMed]

76. Mao, N.; Yin, P.; Wang, Q.; Liu, M.; Dong, J.; Zhang, X.; Xie, H.; Hong, N. Added Value of Radiomics on Mammography for Breast Cancer Diagnosis: A Feasibility Study. J. Am. Coll. Radiol. 2019, 16, 485-491. [CrossRef] [PubMed]

77. Jaffe, T.A.; Wickersham, N.W.; Sullivan, D.C. Quantitative imaging in oncology patients: Part 2, oncologists' opinions and expectations at major U.S. cancer centers. AJR Am. J. Roentgenol. 2010, 195, W19-W30. [CrossRef] [PubMed]

78. Liang, C.; Bian, Z.; Lv, W.; Chen, S.; Zeng, D.; Ma, J. A computer-aided diagnosis scheme of breast lesion classification using GLGLM and shape features: Combined-view and multi-classifiers. Phys. Med. 2018, 55, 61-72. [CrossRef]

79. Robinson, K.; Li, H.; Lan, L.; Schacht, D.; Giger, M. Radiomics robustness assessment and classification evaluation: A two-stage method demonstrated on multivendor FFDM. Med. Phys. 2019, 46, 2145-2156. [CrossRef]

80. Ye, D.M.; Wang, H.T.; Yu, T. The Application of Radiomics in Breast MRI: A Review. Technol. Cancer Res. Treat. 2020, 19, 1533033820916191. [CrossRef]

81. Tagliafico, A.S.; Piana, M.; Schenone, D.; Lai, R.; Massone, A.M.; Houssami, N. Overview of radiomics in breast cancer diagnosis and prognostication. Breast 2020, 49, 74-80. [CrossRef]

82. Sezgin, G.; Coskun, M. The role of rare breast cancers in the false negative strain elastography results. Radiol. Med. 2021, 126, 349-355. [CrossRef]

83. Holli-Helenius, K.; Salminen, A.; Rinta-Kiikka, I.; Koskivuo, I.; Brück, N.; Boström, P.; Parkkola, R. MRI texture analysis in differentiating luminal A and luminal B breast cancer molecular subtypes-A feasibility study. BMC Med. Imaging 2017, 17, 69. [CrossRef]

84. Waugh, S.A.; Purdie, C.A.; Jordan, L.B.; Vinnicombe, S.; Lerski, R.A.; Martin, P.; Thompson, A.M. Magnetic resonance imaging texture analysis classification of primary breast cancer. Eur. Radiol. 2016, 26, 322-330. [CrossRef]

85. Li, H.; Zhu, Y.; Burnside, E.S.; Huang, E.; Drukker, K.; Hoadley, K.A.; Fan, C.; Conzen, S.D.; Zuley, M.; Net, J.M.; et al. Quantitative MRI radiomics in the prediction of molecular classifications of breast cancer subtypes in the TCGA/TCIA data set. NPJ Breast Cancer 2016, 2, 16012. [CrossRef]

86. Leithner, D.; Horvat, J.V.; Marino, M.A.; Bernard-Davila, B.; Jochelson, M.S.; Ochoa-Albiztegui, R.E.; Martinez, D.F.; Morris, E.A.; Thakur, S.; Pinker, K. Radiomic signatures with contrast-enhanced magnetic resonance imaging for the assessment of breast cancer receptor status and molecular subtypes: Initial results. Breast Cancer Res. 2019, 21, 106. [CrossRef] 
87. Saha, A.; Harowicz, M.R.; Grimm, L.J.; Kim, C.E.; Ghate, S.V.; Walsh, R.; Mazurowski, M.A. A machine learning approach to radiogenomics of breast cancer: A study of 922 subjects and 529 DCE-MRI features. Br. J. Cancer 2018, 119, 508-516. [CrossRef] [PubMed]

88. Guo, W.; Li, H.; Zhu, Y.; Lan, L.; Yang, S.; Drukker, K.; Morris, E.; Burnside, E.; Whitman, G.; Giger, M.L.; et al. Prediction of clinical phenotypes in invasive breast carcinomas from the integration of radiomics and genomics data. J. Med. Imaging 2015, 2, 041007. [CrossRef] [PubMed]

89. Zhang, Y.; Zhu, Y.; Zhang, K.; Liu, Y.; Cui, J.; Tao, J.; Wang, Y.; Wang, S. Invasive ductal breast cancer: Preoperative predict Ki-67 index based on radiomics of ADC maps. Radiol. Med. 2020, 125, 109-116. [CrossRef]

90. Braman, N.; Prasanna, P.; Whitney, J.; Singh, S.; Beig, N.; Etesami, M.; Bates, D.D.B.; Gallagher, K.; Bloch, B.N.; Vulchi, M.; et al. Association of Peritumoral Radiomics With Tumor Biology and Pathologic Response to Preoperative Targeted Therapy for HER2 (ERBB2)-Positive Breast Cancer. JAMA Netw. Open 2019, 2, e192561. [CrossRef] [PubMed]

91. Dumitrescu, R.G. Interplay between Genetic and Epigenetic Changes in Breast Cancer Subtypes. Methods Mol. Biol. 2018, 1856, 19-34. [CrossRef] [PubMed]

92. Jordan, N.V.; Bardia, A.; Wittner, B.S.; Benes, C.; Ligorio, M.; Zheng, Y.; Yu, M.; Sundaresan, T.K.; Licausi, J.A.; Desai, R.; et al. HER2 expression identifies dynamic functional states within circulating breast cancer cells. Nature 2016, 537, 102-106. [CrossRef] [PubMed]

93. Dong, Y.; Feng, Q.; Yang, W.; Lu, Z.; Deng, C.; Zhang, L.; Lian, Z.; Liu, J.; Luo, X.; Pei, S.; et al. Preoperative prediction of sentinel lymph node metastasis in breast cancer based on radiomics of T2-weighted fat-suppression and diffusion-weighted MRI. Eur. Radiol. 2018, 28, 582-591. [CrossRef] [PubMed]

94. Cui, X.; Wang, N.; Zhao, Y.; Chen, S.; Li, S.; Xu, M.; Chai, R. Preoperative Prediction of Axillary Lymph Node Metastasis in Breast Cancer using Radiomics Features of DCE-MRI. Sci. Rep. 2019, 9, 2240. [CrossRef]

95. Huang, S.Y.; Franc, B.L.; Harnish, R.J.; Liu, G.; Mitra, D. Exploration of PET and MRI radiomic features for decoding breast cancer phenotypes and prognosis. NPJ Breast Cancer 2018, 4, 24. [CrossRef]

96. Chai, R.; Ma, H.; Xu, M.; Arefan, D.; Cui, X.; Liu, Y.; Zhang, L.; Wu, S.; Xu, K. Differentiating axillary lymph node metastasis in invasive breast cancer patients: A comparison of radiomic signatures from multiparametric breast MR sequences. J. Magn. Reson. Imaging 2019, 50, 1125-1132. [CrossRef]

97. Liu, Z.; Feng, B.; Li, C.; Chen, Y.; Chen, Q.; Li, X.; Guan, J.; Chen, X.; Cui, E.; Li, R.; et al. Preoperative prediction of lymphovascular invasion in invasive breast cancer with dynamic contrast-enhanced-MRI-based radiomics. J. Magn. Reson. Imaging 2019, 50, 847-857. [CrossRef]

98. Zheng, X.; Yao, Z.; Huang, Y. Deep learning radiomics can predict axillary lymph node status in early-stage breast cancer. Nat. Commun. 2020, 11, 1236. [CrossRef]

99. Tsougos, I.; Vamvakas, A.; Kappas, C.; Fezoulidis, I.; Vassiou, K. Application of Radiomics and Decision Support Systems for Breast MR Differential Diagnosis. Comput. Math. Methods Med. 2018, 2018, 7417126. [CrossRef]

100. Braman, N.M.; Etesami, M.; Prasanna, P.; Dubchuk, C.; Gilmore, H.; Tiwari, P.; Plecha, D.; Madabhushi, A. Intratumoral and peritumoral radiomics for the pretreatment prediction of pathological complete response to neoadjuvant chemotherapy based on breast DCE-MRI. Breast Cancer Res. 2017, 19, 57. [CrossRef]

101. Drukker, K.; Edwards, A.; Doyle, C. Breast MRI radiomics for the pretreatment prediction of response to neoadjuvant chemotherapy in node-positive breast cancer patients. J. Med. Imaging 2019, 6, 034502. [CrossRef]

102. Parikh, J.; Selmi, M.; Charles-Edwards, G.; Glendenning, J.; Ganeshan, B.; Verma, H.; Mansi, J.; Harries, M.; Tutt, A.; Goh, V. Changes in primary breast cancer heterogeneity may augment midtreatment MR imaging assessment of response to neoadjuvant chemotherapy. Radiology 2014, 272, 100-112. [CrossRef]

103. Kim, Y.; Kim, S.H.; Song, B.J.; Kang, B.J.; Yim, K.I.; Lee, A.; Nam, Y. Early Prediction of Response to Neoadjuvant Chemotherapy Using Dynamic Contrast-Enhanced MRI and Ultrasound in Breast Cancer. Korean J. Radiol. 2018, 19, 682-691. [CrossRef] [PubMed]

104. Park, H.; Lim, Y. Radiomics Signature on Magnetic Resonance Imaging: Association with Disease-Free Survival in Patients with Invasive Breast Cancer. Clin. Cancer Res. 2018, 24, 4705-4714. [CrossRef] [PubMed]

105. Li, H.; Zhu, Y.; Burnside, E.S.; Drukker, K.; Hoadley, K.A.; Fan, C.; Conzen, S.D.; Whitman, G.J.; Sutton, E.J.; Net, J.M.; et al. MR Imaging Radiomics Signatures for Predicting the Risk of Breast Cancer Recurrence as Given by Research Versions of MammaPrint, Oncotype DX, and PAM50 Gene Assays. Radiology 2016, 281, 382-391. [CrossRef] [PubMed]

106. Sun, R.J.; Fang, M.J.; Tang, L.; Li, X.T.; Lu, Q.Y.; Dong, D.; Tian, J.; Sun, Y.S. CT-based deep learning radiomics analysis for evaluation of serosa invasion in advanced gastric cancer. Eur. J. Radiol. 2020, 132, 109277. [CrossRef] [PubMed]

107. Feng, Q.X.; Liu, C.; Qi, L.; Sun, S.W.; Song, Y.; Yang, G.; Zhang, Y.D.; Liu, X.S. An Intelligent Clinical Decision Support System for Preoperative Prediction of Lymph Node Metastasis in Gastric Cancer. J. Am. Coll. Radiol. 2019, 16, 952-960. [CrossRef] [PubMed]

108. Dong, D.; Fang, M.J.; Tang, L.; Shan, X.H.; Gao, J.B.; Giganti, F.; Wang, R.P.; Chen, X.; Wang, X.X.; Palumbo, D.; et al. Deep learning radiomic nomogram can predict the number of lymph node metastasis in locally advanced gastric cancer: An international multicenter study. Ann. Oncol. 2020, 31, 912-920. [CrossRef]

109. Li, J.; Dong, D.; Fang, M.; Wang, R.; Tian, J.; Li, H.; Gao, J. Dual-energy CT-based deep learning radiomics can improve lymph node metastasis risk prediction for gastric cancer. Eur. Radiol. 2020, 30, 2324-2333. [CrossRef] 
110. Yardımc1, A.H.; Koçak, B.; Turan Bektaş, C.; Sel, İ.; Yarıkkaya, E.; Dursun, N.; Bektaş, H.; Usul Afşar, Ç.; Gürsu, R.U.; Kılıçkesmez, Ö. Tubular gastric adenocarcinoma: Machine learning-based CT texture analysis for predicting lymphovascular and perineural invasion. Diagn. Interv. Radiol. 2020, 26, 515-522. [CrossRef]

111. Yang, J.; Wu, Q.; Xu, L.; Wang, Z.; Su, K.; Liu, R.; Yen, E.A.; Liu, S.; Qin, J.; Rong, Y.; et al. Integrating tumor and nodal radiomics to predict lymph node metastasis in gastric cancer. Radiother. Oncol. 2020, 150, 89-96. [CrossRef]

112. Wang, Y.; Liu, W.; Yu, Y.; Liu, J.J.; Xue, H.D.; Qi, Y.F.; Lei, J.; Yu, J.C.; Jin, Z.Y. CT radiomics nomogram for the preoperative prediction of lymph node metastasis in gastric cancer. Eur. Radiol. 2020, 30, 976-986. [CrossRef]

113. Wang, L.; Gong, J.; Huang, X.; Lin, G.; Zheng, B.; Chen, J.; Xie, J.; Lin, R.; Duan, Q.; Lin, W. CT-based radiomics nomogram for preoperative prediction of No.10 lymph nodes metastasis in advanced proximal gastric cancer. Eur. J. Surg. Oncol. 2021, 47, 1458-1465. [CrossRef]

114. Jiang, Y.; Wang, W.; Chen, C.; Zhang, X.; Zha, X.; Lv, W.; Xie, J.; Huang, W.; Sun, Z.; Hu, Y.; et al. Radiomics Signature on Computed Tomography Imaging: Association with Lymph Node Metastasis in Patients with Gastric Cancer. Front. Oncol. 2019, 9, 340. [CrossRef]

115. Gao, X.; Ma, T.; Cui, J.; Zhang, Y.; Wang, L.; Li, H.; Ye, Z. A CT-based Radiomics Model for Prediction of Lymph Node Metastasis in Early Stage Gastric Cancer. Acad. Radiol. 2020, 26, e155-e164. [CrossRef]

116. Wang, Y.; Jin, Z.Y. Radiomics approaches in gastric cancer: A frontier in clinical decision making. Chin. Med. J. 2019, 132, 1983-1989. [CrossRef] [PubMed]

117. Gao, X.; Ma, T.; Cui, J.; Zhang, Y.; Wang, L.; Li, H.; Ye, Z. A radiomics-based model for prediction of lymph node metastasis in gastric cancer. Eur. J. Radiol. 2020, 129, 109069. [CrossRef] [PubMed]

118. Sun, K.-Y.; Hu, H.-T.; Chen, S.-L.; Ye, J.-N.; Li, G.-H.; Chen, L.-D.; Peng, J.-J.; Feng, S.-T.; Yuan, Y.-J.; Hou, X.; et al. CT-based radiomics scores predict response to neoadjuvant chemotherapy and survival in patients with gastric cancer. BMC Cancer 2020, 20, 468. [CrossRef] [PubMed]

119. Zhang, L.; Dong, D.; Zhang, W.; Hao, X.; Fang, M.; Wang, S.; Li, W.; Liu, Z.; Wang, R.; Zhou, J.; et al. A deep learning risk prediction model for overall survival in patients with gastric cancer: A multicenter study. Radiother. Oncol. 2020, 150, 73-80. [CrossRef]

120. Li, J.; Zhang, C.; Wei, J.; Zheng, P.; Zhang, H.; Xie, Y.; Bai, J.; Zhu, Z.; Zhou, K.; Liang, X.; et al. Intratumoral and Peritumoral Radiomics of Contrast-Enhanced CT for Prediction of Disease-Free Survival and Chemotherapy Response in Stage II/III Gastric Cancer. Front. Oncol. 2020, 10, 552270. [CrossRef]

121. Li, Z.; Zhang, D.; Dai, Y.; Dong, J.; Wu, L.; Li, Y.; Cheng, Z.; Ding, Y.; Liu, Z. Computed tomography-based radiomics for prediction of neoadjuvant chemotherapy outcomes in locally advanced gastric cancer: A pilot study. Chin. J. Cancer Res. Chung-Kuo Yen Cheng Yen Chiu 2018, 30, 406-414. [CrossRef] [PubMed]

122. Chen, X.; Yang, Z.; Yang, J.; Liao, Y.; Pang, P.; Fan, W.; Chen, X. Radiomics analysis of contrast-enhanced CT predicts lymphovascular invasion and disease outcome in gastric cancer: A preliminary study. Cancer Imaging Off. Publ. Int. Cancer Imaging Soc. 2020, 20, 24. [CrossRef] [PubMed]

123. Tan, J.W.; Wang, L.; Chen, Y.; Xi, W.; Ji, J.; Wang, L.; Xu, X.; Zou, L.K.; Feng, J.X.; Zhang, J.; et al. Predicting Chemotherapeutic Response for Far-advanced Gastric Cancer by Radiomics with Deep Learning Semi-automatic Segmentation. J. Cancer 2020, 11, 7224-7236. [CrossRef] [PubMed]

124. Jiang, Y.; Chen, C.; Xie, J.; Wang, W.; Zha, X.; Lv, W.; Chen, H.; Hu, Y.; Li, T.; Yu, J.; et al. Radiomics signature of computed tomography imaging for prediction of survival and chemotherapeutic benefits in gastric cancer. EBioMedicine 2018, 36, 171-182. [CrossRef] [PubMed]

125. Li, W.; Zhang, L.; Tian, C.; Song, H.; Fang, M.; Hu, C.; Zang, Y.; Cao, Y.; Dai, S.; Wang, F.; et al. Prognostic value of computed tomography radiomics features in patients with gastric cancer following curative resection. Eur. Radiol. 2019, 29, 3079-3089. [CrossRef] [PubMed]

126. Li, Q.; Qi, L.; Feng, Q.-X.; Liu, C.; Sun, S.-W.; Zhang, J.; Yang, G.; Ge, Y.-Q.; Zhang, Y.-D.; Liu, X.-S. Machine Learning-Based Computational Models Derived From Large-Scale Radiographic-Radiomic Images Can Help Predict Adverse Histopathological Status of Gastric Cancer. Clin. Transl. Gastroenterol. 2019, 10, e00079. [CrossRef]

127. Zhang, L.; Kang, L.; Li, G.; Zhang, X.; Ren, J.; Shi, Z.; Li, J.; Yu, S. Computed tomography-based radiomics model for discriminating the risk stratification of gastrointestinal stromal tumors. Radiol. Med. 2020, 125, 465-473. [CrossRef]

128. Zhou, Y.; Ma, X.L. Prediction of Overall Survival and Progression-Free Survival by the (18)F-FDG PET/CT Radiomic Features in Patients with Primary Gastric Diffuse Large B-Cell Lymphoma. Contrast Media Mol. Imaging 2019, 2019, 5963607. [CrossRef]

129. Mazzei, M.A.; Giacomo, L.D.; Bagnacci, G.; Nardone, V.; Gentili, F.; Lucii, G.; Tini, P.; Marrelli, D.; Morgagni, P.; Mura, G.; et al. Delta-radiomics and response to neoadjuvant treatment in locally advanced gastric cancer-A multicenter study of GIRCG (Italian Research Group for Gastric Cancer). Quant. Imaging Med. Surg. 2021, 11, 2376. [CrossRef]

130. Wang, Y.; Yu, Y.; Han, W.; Zhang, Y.J.; Jiang, L.; Xue, H.D.; Lei, J.; Jin, Z.Y.; Yu, J.C. CT Radiomics for Distinction of Human Epidermal Growth Factor Receptor 2 Negative Gastric Cancer. Acad. Radiol. 2021, 28, e86-e92. [CrossRef]

131. Wang, N.; Wang, X.; Li, W.; Ye, H.; Bai, H.; Wu, J.; Chen, M. Contrast-Enhanced CT Parameters of Gastric Adenocarcinoma: Can Radiomic Features Be Surrogate Biomarkers for HER2 Over-Expression Status? Cancer Manag. Res. 2020, 12, 1211-1219. [CrossRef] 
132. Marin, D.; Cappabianca, S.; Serra, N.; Sica, A.; Lassandro, F. CT Appearance of Hepatocellular Carcinoma after Locoregional Treatments: A Comprehensive Review. Gastroenterol. Res. Pract. 2015, 2015, 670965. [CrossRef]

133. Park, H.J.; Park, B.; Lee, S.S. Radiomics and Deep Learning: Hepatic Applications. Korean J. Radiol. 2020, 21, 387-401. [CrossRef]

134. Fiz, F.; Viganò, L.; Gennaro, N.; Costa, G.; La Bella, L.; Boichuk, A.; Cavinato, L.; Sollini, M.; Politi, L.S.; Chiti, A.; et al. Radiomics of Liver Metastases: A Systematic Review. Cancers 2020, 12, 2881. [CrossRef]

135. Dreher, C.; Linde, P.; Boda-Heggemann, J.; Baessler, B. Radiomics for liver tumours. Strahlenther. Onkol. 2020, 196, 888-899. [CrossRef]

136. Reginelli, A.; Vanzulli, A.; Sgrazzutti, C.; Caschera, L.; Serra, N.; Raucci, A.; Urraro, F.; Cappabianca, S. Vascular microinvasion from hepatocellular carcinoma: CT findings and pathologic correlation for the best therapeutic strategies. Med. Oncol. 2017, 34, 93. [CrossRef] [PubMed]

137. Wei, J.; Jiang, H.; Gu, D.; Niu, M.; Fu, F.; Han, Y.; Song, B.; Tian, J. Radiomics in liver diseases: Current progress and future opportunities. Liver Int. Off. J. Int. Assoc. Study Liver 2020, 40, 2050-2063. [CrossRef] [PubMed]

138. Ji, G.W.; Zhu, F.P. Radiomic Features at Contrast-enhanced CT Predict Recurrence in Early Stage Hepatocellular Carcinoma: A Multi-Institutional Study. Radiology 2020, 294, 568-579. [CrossRef] [PubMed]

139. Zhang, J.; Wang, X.; Zhang, L.; Yao, L.; Xue, X.; Zhang, S.; Li, X.; Chen, Y.; Pang, P.; Sun, D.; et al. Radiomics predict postoperative survival of patients with primary liver cancer with different pathological types. Ann. Transl. Med. 2020, 8, 820. [CrossRef]

140. Wang, X.H.; Long, L.H.; Cui, Y.; Jia, A.Y.; Zhu, X.G.; Wang, H.Z.; Wang, Z.; Zhan, C.M.; Wang, Z.H.; Wang, W.H. MRI-based radiomics model for preoperative prediction of 5-year survival in patients with hepatocellular carcinoma. Br. J. Cancer 2020, 122, 978-985. [CrossRef] [PubMed]

141. Zhang, Z.; Chen, J.; Jiang, H.; Wei, Y.; Zhang, X.; Cao, L.; Duan, T.; Ye, Z.; Yao, S.; Pan, X.; et al. Gadoxetic acid-enhanced MRI radiomics signature: Prediction of clinical outcome in hepatocellular carcinoma after surgical resection. Ann. Transl. Med. 2020, 8, 870. [CrossRef]

142. Song, W.; Yu, X.; Guo, D.; Liu, H.; Tang, Z.; Liu, X.; Zhou, J.; Zhang, H.; Liu, Y.; Liu, X. MRI-Based Radiomics: Associations With the Recurrence-Free Survival of Patients With Hepatocellular Carcinoma Treated With Conventional Transcatheter Arterial Chemoembolization. J. Magn. Reson. Imaging 2020, 52, 461-473. [CrossRef]

143. Ma, Q.P.; He, X.L.; Li, K.; Wang, J.F.; Zeng, Q.J.; Xu, E.J.; He, X.Q.; Li, S.Y.; Kun, W.; Zheng, R.Q.; et al. Dynamic Contrast-Enhanced Ultrasound Radiomics for Hepatocellular Carcinoma Recurrence Prediction After Thermal Ablation. Mol. Imaging Biol. 2021, 23, 572-585. [CrossRef]

144. Lincke, T.; Zech, C.J. Liver metastases: Detection and staging. Eur. J. Radiol. 2017, 97, 76-82. [CrossRef]

145. Taghavi, M.; Trebeschi, S.; Simões, R.; Meek, D.B.; Beckers, R.C.J.; Lambregts, D.M.J.; Verhoef, C.; Houwers, J.B.; van der Heide, U.A.; Beets-Tan, R.G.H.; et al. Machine learning-based analysis of CT radiomics model for prediction of colorectal metachronous liver metastases. Abdom. Radiol. 2021, 46, 249-256. [CrossRef] [PubMed]

146. Bipat, S.; Niekel, M.C.; Stoker, J. Diagnostic Imaging of Colorectal Liver Metastases with CT, Purpose: Methods: Results: Conclusion. Radiology 2010, 257, 674-684. [CrossRef]

147. Liu, M.; Lu, J. MRI-based radiomics nomogram to predict synchronous liver metastasis in primary rectal cancer patients. Cancer Med. 2020, 9, 5155-5163. [CrossRef] [PubMed]

148. Ravanelli, M.; Agazzi, G.M.; Tononcelli, E.; Roca, E.; Cabassa, P.; Baiocchi, G.; Berruti, A.; Maroldi, R.; Farina, D. Texture features of colorectal liver metastases on pretreatment contrast-enhanced CT may predict response and prognosis in patients treated with bevacizumab-containing chemotherapy: A pilot study including comparison with standard chemotherapy. Radiol. Med. 2019, 124, 877-886. [CrossRef] [PubMed]

149. Nakanishi, R.; Oki, E.; Hasuda, H.; Sano, E. Radiomics Texture Analysis for the Identification of Colorectal Liver Metastases Sensitive to First-Line Oxaliplatin-Based Chemotherapy. Ann. Surg. Oncol. 2021, 28, 2975-2985. [CrossRef] [PubMed]

150. Hu, H.T.; Shan, Q.Y.; Chen, S.L.; Li, B.; Feng, S.T.; Xu, E.J.; Li, X.; Long, J.Y.; Xie, X.Y.; Lu, M.D.; et al. CT-based radiomics for preoperative prediction of early recurrent hepatocellular carcinoma: Technical reproducibility of acquisition and scanners. Radiol. Med. 2020, 125, 697-705. [CrossRef] [PubMed]

151. Beckers, R.C.J.; Lambregts, D.M.J.; Lahaye, M.J.; Rao, S.X.; Kleinen, K.; Grootscholten, C.; Beets, G.L.; Beets-Tan, R.G.H.; Maas, M. Advanced imaging to predict response to chemotherapy in colorectal liver metastases-A systematic review. HPB 2018, 20, 120-127. [CrossRef]

152. Spatola, C.; Privitera, G.; Milazzotto, R.; Tocco, A.; Acquaviva, G.; Marletta, F.; Marino, L.; Di Grazia, A.; Salvo, R.; Cartia, G.; et al. Trends in combined radio-chemotherapy for locally advanced rectal cancer: A survey among radiation oncology centers of Sicily region on behalf of AIRO. Radiol. Med. 2019, 124, 671-681. [CrossRef]

153. Grassi, R.; Rambaldi, P.F.; Di Grezia, G.; Mansi, L.; Cuccurullo, V.; Cirillo, A.; Riegler, G.; Cappabianca, S.; Rotondo, A. Inflammatory bowel disease: Value in diagnosis and management of MDCT-enteroclysis and 99mTc-HMPAO labeled leukocyte scintigraphy. Abdom. Imaging 2011, 36, 372-381. [CrossRef]

154. Somma, F.; Faggian, A.; Serra, N.; Gatta, G.; Iacobellis, F.; Berritto, D.; Reginelli, A.; Di Mizio, V.; Cappabianca, S.; Di Mizio, R.; et al. Bowel intussusceptions in adults: The role of imaging. Radiol. Med. 2015, 120, 105-117. [CrossRef]

155. Bertocchi, E.; Barugola, G.; Nicosia, L.; Mazzola, R.; Ricchetti, F.; Dell'Abate, P.; Alongi, F.; Ruffo, G. A comparative analysis between radiation dose intensification and conventional fractionation in neoadjuvant locally advanced rectal cancer: A monocentric prospective observational study. Radiol. Med. 2020, 125, 990-998. [CrossRef] [PubMed] 
156. van de Velde, C.J.; Boelens, P.G.; Borras, J.M.; Coebergh, J.W.; Cervantes, A.; Blomqvist, L.; Beets-Tan, R.G.; van den Broek, C.B.; Brown, G.; Van Cutsem, E.; et al. EURECCA colorectal: Multidisciplinary management: European consensus conference colon \& rectum. Eur. J. Cancer 2014, 50, 1-e1-1-e34. [CrossRef]

157. Kapiteijn, E.; Marijnen, C.A.; Nagtegaal, I.D.; Putter, H.; Steup, W.H.; Wiggers, T.; Rutten, H.J.; Pahlman, L.; Glimelius, B.; van Krieken, J.H.; et al. Preoperative radiotherapy combined with total mesorectal excision for resectable rectal cancer. N. Engl. J. Med. 2001, 345, 638-646. [CrossRef] [PubMed]

158. Crimì, F.; Capelli, G.; Spolverato, G.; Bao, Q.R.; Florio, A.; Milite Rossi, S.; Cecchin, D.; Albertoni, L.; Campi, C.; Pucciarelli, S.; et al. MRI T2-weighted sequences-based texture analysis (TA) as a predictor of response to neoadjuvant chemo-radiotherapy (nCRT) in patients with locally advanced rectal cancer (LARC). Radiol. Med. 2020, 125, 1216-1224. [CrossRef] [PubMed]

159. Dicle, O.; Obuz, F.; Cakmakci, H. Differentiation of recurrent rectal cancer and scarring with dynamic MR imaging. Br. J. Radiol. 1999, 72, 1155-1159. [CrossRef] [PubMed]

160. Rosa, C.; Caravatta, L.; Di Tommaso, M.; Fasciolo, D.; Gasparini, L.; Di Guglielmo, F.C.; Augurio, A.; Vinciguerra, A.; Vecchi, C.; Genovesi, D. Cone-beam computed tomography for organ motion evaluation in locally advanced rectal cancer patients. Radiol. Med. 2021, 126, 147-154. [CrossRef]

161. Glynne-Jones, R.; Wyrwicz, L.; Tiret, E.; Brown, G.; Rödel, C.; Cervantes, A.; Arnold, D. Rectal cancer: ESMO Clinical Practice Guidelines for diagnosis, treatment and follow-up. Ann. Oncol. 2018, 29, iv263. [CrossRef] [PubMed]

162. Reginelli, A.; Clemente, A.; Sangiovanni, A.; Nardone, V.; Selvaggi, F.; Sciaudone, G.; Ciardiello, F.; Martinelli, E.; Grassi, R.; Cappabianca, S. Endorectal Ultrasound and Magnetic Resonance Imaging for Rectal Cancer Staging: A Modern Multimodality Approach. J. Clin. Med. 2021, 10, 641. [CrossRef]

163. Beets-Tan, R.G.H.; Lambregts, D.M.J.; Maas, M.; Bipat, S.; Barbaro, B.; Curvo-Semedo, L.; Fenlon, H.M.; Gollub, M.J.; Gourtsoyianni, S.; Halligan, S.; et al. Magnetic resonance imaging for clinical management of rectal cancer: Updated recommendations from the 2016 European Society of Gastrointestinal and Abdominal Radiology (ESGAR) consensus meeting. Eur. Radiol. 2018, 28, 1465-1475. [CrossRef] [PubMed]

164. Fornell-Perez, R.; Vivas-Escalona, V.; Aranda-Sanchez, J.; Gonzalez-Dominguez, M.C.; Rubio-Garcia, J.; Aleman-Flores, P.; Lozano-Rodriguez, A.; Porcel-de-Peralta, G.; Loro-Ferrer, J.F. Primary and post-chemoradiotherapy MRI detection of extramural venous invasion in rectal cancer: The role of diffusion-weighted imaging. Radiol. Med. 2020, 125, 522-530. [CrossRef] [PubMed]

165. Ciolina, M.; Caruso, D.; De Santis, D.; Zerunian, M.; Rengo, M.; Alfieri, N.; Musio, D.; De Felice, F.; Ciardi, A.; Tombolini, V.; et al. Dynamic contrast-enhanced magnetic resonance imaging in locally advanced rectal cancer: Role of perfusion parameters in the assessment of response to treatment. Radiol. Med. 2019, 124, 331-338. [CrossRef] [PubMed]

166. Cusumano, D.; Meijer, G.; Lenkowicz, J.; Chiloiro, G.; Boldrini, L.; Masciocchi, C.; Dinapoli, N.; Gatta, R.; Casà, C.; Damiani, A.; et al. A field strength independent MR radiomics model to predict pathological complete response in locally advanced rectal cancer. Radiol. Med. 2021, 126, 421-429. [CrossRef] [PubMed]

167. Mahadevan, L.S.; Zhong, J.; Venkatesulu, B.; Kaur, H.; Bhide, S.; Minsky, B.; Chu, W.; Intven, M.; van der Heide, U.A.; van Triest, B.; et al. Imaging predictors of treatment outcomes in rectal cancer: An overview. Crit. Rev. Oncol. Hematol. 2018, 129, 153-162. [CrossRef] [PubMed]

168. Scialpi, M.; Reginelli, A.; D’Andrea, A.; Gravante, S.; Falcone, G.; Baccari, P.; Manganaro, L.; Palumbo, B.; Cappabianca, S. Pancreatic tumors imaging: An update. Int. J. Surg. 2016, 28 (Suppl. 1), S142-S155. [CrossRef] [PubMed]

169. Aker, M.; Ganeshan, B.; Afaq, A.; Wan, S.; Groves, A.M.; Arulampalam, T. Magnetic Resonance Texture Analysis in Identifying Complete Pathological Response to Neoadjuvant Treatment in Locally Advanced Rectal Cancer. Dis. Colon Rectum 2019, 62, 163-170. [CrossRef]

170. De Cecco, C.N.; Ganeshan, B.; Ciolina, M.; Rengo, M.; Meinel, F.G.; Musio, D.; De Felice, F.; Raffetto, N.; Tombolini, V.; Laghi, A. Texture analysis as imaging biomarker of tumoral response to neoadjuvant chemoradiotherapy in rectal cancer patients studied with 3-T magnetic resonance. Investig. Radiol. 2015, 50, 239-245. [CrossRef]

171. Horvat, N.; Veeraraghavan, H.; Khan, M.; Blazic, I.; Zheng, J.; Capanu, M.; Sala, E.; Garcia-Aguilar, J.; Gollub, M.J.; Petkovska, I. MR Imaging of Rectal Cancer: Radiomics Analysis to Assess Treatment Response after Neoadjuvant Therapy. Radiology 2018, 287, 833-843. [CrossRef] [PubMed]

172. Nie, K.; Shi, L.; Chen, Q.; Hu, X.; Jabbour, S.K.; Yue, N.; Niu, T.; Sun, X. Rectal Cancer: Assessment of Neoadjuvant Chemoradiation Outcome based on Radiomics of Multiparametric MRI. Clin. Cancer Res. 2016, 22, 5256-5264. [CrossRef] [PubMed]

173. Chen, F.; Ma, X.; Li, S.; Li, Z.; Jia, Y.; Xia, Y.; Wang, M.; Shen, F.; Lu, J. MRI-Based Radiomics of Rectal Cancer: Assessment of the Local Recurrence at the Site of Anastomosis. Acad. Radiol. 2020, in press. [CrossRef] [PubMed]

174. O'Connor, J.P.B.; Rose, C.J.; Waterton, J.C.; Carano, R.A.D.; Parker, G.J.M.; Jackson, A. Imaging intratumor heterogeneity: Role in therapy response, resistance, and clinical outcome. Clin. Cancer Res. 2015, 21, 249-257. [CrossRef]

175. Wan, L.; Peng, W.; Zou, S.; Ye, F.; Geng, Y.; Ouyang, H.; Zhao, X.; Zhang, H. MRI-based delta-radiomics are predictive of pathological complete response after neoadjuvant chemoradiotherapy in locally advanced rectal cancer. Acad. Radiol. 2020. [CrossRef]

176. Chen, L.-D.; Li, W.; Xian, M.-F.; Zheng, X.; Lin, Y.; Liu, B.-X.; Lin, M.-X.; Li, X.; Zheng, Y.-L.; Xie, X.-Y.; et al. Preoperative prediction of tumour deposits in rectal cancer by an artificial neural network-based US radiomics model. Eur. Radiol. 2020, 30, 1969-1979. [CrossRef] 
177. Gopal, P.; Lu, P.; Ayers, G.D.; Herline, A.J.; Washington, M.K. Tumor deposits in rectal adenocarcinoma after neoadjuvant chemoradiation are associated with poor prognosis. Mod. Pathol. 2014, 27, 1281-1287. [CrossRef] [PubMed]

178. Yuan, Z.; Frazer, M.; Zhang, G.G.; Latifi, K.; Moros, E.G.; Feygelman, V.; Felder, S.; Sanchez, J.; Dessureault, S.; Imanirad, I.; et al. CT-based radiomic features to predict pathological response in rectal cancer: A retrospective cohort study. J. Med. Imaging Radiat. Oncol. 2020, 64, 444-449. [CrossRef]

179. Bibault, J.-E.; Giraud, P.; Housset, M.; Durdux, C.; Taieb, J.; Berger, A.; Coriat, R.; Chaussade, S.; Dousset, B.; Nordlinger, B.; et al. Deep Learning and Radiomics predict complete response after neo-adjuvant chemoradiation for locally advanced rectal cancer. Sci. Rep. 2018, 8, 12611. [CrossRef]

180. Chee, C.G.; Kim, Y.H.; Lee, K.H.; Lee, Y.J.; Park, J.H.; Lee, H.S.; Ahn, S.; Kim, B. CT texture analysis in patients with locally advanced rectal cancer treated with neoadjuvant chemoradiotherapy: A potential imaging biomarker for treatment response and prognosis. PLoS ONE 2017, 12, e0182883. [CrossRef]

181. Chiloiro, G.; Rodriguez-Carnero, P.; Lenkowicz, J.; Casà, C.; Masciocchi, C.; Boldrini, L.; Cusumano, D.; Dinapoli, N.; Meldolesi, E.; Carano, D.; et al. Delta Radiomics Can Predict Distant Metastasis in Locally Advanced Rectal Cancer: The Challenge to Personalize the Cure. Front. Oncol. 2020, 10, 595012. [CrossRef]

182. Liu, Z.; Meng, X.; Zhang, H.; Li, Z.; Liu, J.; Sun, K.; Meng, Y.; Dai, W.; Xie, P.; Ding, Y.; et al. Predicting distant metastasis and chemotherapy benefit in locally advanced rectal cancer. Nat. Commun. 2020, 11, 4308. [CrossRef]

183. Liu, H.; Zhang, C.; Wang, L.; Luo, R.; Li, J.; Zheng, H.; Yin, Q.; Zhang, Z.; Duan, S.; Li, X.; et al. MRI radiomics analysis for predicting preoperative synchronous distant metastasis in patients with rectal cancer. Eur. Radiol. 2019, 29, 4418-4426. [CrossRef] [PubMed]

184. Nardone, V.; Reginelli, A.; Scala, F. Magnetic-Resonance-Imaging Texture Analysis Predicts Early Progression in Rectal Cancer Patients Undergoing Neoadjuvant Chemoradiation. Gastroenterol. Res. Pr. 2019, 2019, 8505798. [CrossRef]

185. Staal, F.C.R.; van der Reijd, D.J.; Taghavi, M.; Lambregts, D.M.J.; Beets-Tan, R.G.H.; Maas, M. Radiomics for the Prediction of Treatment Outcome and Survival in Patients with Colorectal Cancer: A Systematic Review. Clin. Colorectal Cancer 2021, 20, 52-71. [CrossRef] [PubMed]

186. Di Re, A.M.; Sun, Y. MRI radiomics in the prediction of therapeutic response to neoadjuvant therapy for locoregionally advanced rectal cancer: A systematic review. Expert Rev. Anticancer 2021, 21, 425-449. [CrossRef]

187. Kozikowski, M.; Suarez-Ibarrola, R.; Osiecki, R.; Bilski, K.; Gratzke, C.; Shariat, S.F.; Miernik, A.; Dobruch, J. Role of Radiomics in the Prediction of Muscle-invasive Bladder Cancer: A Systematic Review and Meta-analysis. Eur. Urol. Focus 2021, in press. [CrossRef] [PubMed]

188. Stanzione, A.; Gambardella, M.; Cuocolo, R.; Ponsiglione, A.; Romeo, V.; Imbriaco, M. Prostate MRI radiomics: A systematic review and radiomic quality score assessment. Eur. J. Radiol. 2020, 129, 109095. [CrossRef]

189. Lambin, P.; Leijenaar, R.T.H.; Deist, T.M.; Peerlings, J.; de Jong, E.E.C.; van Timmeren, J.; Sanduleanu, S.; Larue, R.; Even, A.J.G.; Jochems, A.; et al. Radiomics: The bridge between medical imaging and personalized medicine. Nat. Rev. Clin. Oncol. 2017, 14, 749-762. [CrossRef]

190. Castaldo, R.; Cavaliere, C. Radiomic and Genomic Machine Learning Method Performance for Prostate Cancer Diagnosis: Systematic Literature Review. J. Med. Internet Res. 2021, 23, e22394. [CrossRef]

191. Tabatabaei, M.; Razaei, A.; Sarrami, A.H.; Saadatpour, Z.; Singhal, A.; Sotoudeh, H. Current Status and Quality of Machine Learning-Based Radiomics Studies for Glioma Grading: A Systematic Review. Oncology 2021, 99, 433-443. [CrossRef]

192. Ugga, L.; Perillo, T. Meningioma MRI radiomics and machine learning: Systematic review, quality score assessment, and meta-analysis. Neuroradiology 2021, 63, 1293-1304. [CrossRef]

193. Kim, H.Y.; Cho, S.J. Classification of true progression after radiotherapy of brain metastasis on MRI using artificial intelligence: A systematic review and meta-analysis. Neuro-Oncol. Adv. 2021, 3, vdab080. [CrossRef]

194. Crombe, A.; Fadli, D.; Italiano, A.; Saut, O.; Buy, X.; Kind, M. Systematic review of sarcomas radiomics studies: Bridging the gap between concepts and clinical applications? Eur. J. Radiol. 2020, 132, 109283. [CrossRef]

195. Gitto, S.; Cuocolo, R.; Albano, D.; Morelli, F.; Pescatori, L.C.; Messina, C.; Imbriaco, M.; Sconfienza, L.M. CT and MRI radiomics of bone and soft-tissue sarcomas: A systematic review of reproducibility and validation strategies. Insights Imaging 2021, 12, 68. [CrossRef]

196. Ursprung, S.; Beer, L.; Bruining, A.; Woitek, R.; Stewart, G.D.; Gallagher, F.A.; Sala, E. Radiomics of computed tomography and magnetic resonance imaging in renal cell carcinoma-a systematic review and meta-analysis. Eur. Radiol. 2020, 30, $3558-3566$. [CrossRef]

197. Mühlbauer, J.; Egen, L.; Kowalewski, K.F.; Grilli, M. Radiomics in Renal Cell Carcinoma-A Systematic Review and Meta-Analysis. Cancers 2021, 13, 1348. [CrossRef] [PubMed]

198. Frood, R.; Burton, C.; Tsoumpas, C.; Frangi, A.F.; Gleeson, F.; Patel, C.; Scarsbrook, A. Baseline PET/CT imaging parameters for prediction of treatment outcome in Hodgkin and diffuse large B cell lymphoma: A systematic review. Eur. J. Nucl. Med. Mol. Imaging 2021, 48, 3198-3220. [CrossRef] [PubMed]

199. Rizzo, S.; Manganaro, L. Computed Tomography Based Radiomics as a Predictor of Survival in Ovarian Cancer Patients: A Systematic Review. Cancers 2021, 13, 573. [CrossRef] [PubMed]

200. Lecointre, L.; Dana, J.; Lodi, M.; Akladios, C.; Gallix, B. Artificial intelligence-based radiomics models in endometrial cancer: A systematic review. Eur. J. Surg. Oncol. 2021. [CrossRef] [PubMed] 
201. Carbonara, R.; Bonomo, P. Investigation of Radiation-Induced Toxicity in Head and Neck Cancer Patients through Radiomics and Machine Learning: A Systematic Review. J. Oncol. 2021, 2021, 5566508. [CrossRef]

202. Creff, G.; Devillers, A.; Depeursinge, A.; Palard-Novello, X.; Acosta, O.; Jegoux, F.; Castelli, J. Evaluation of the Prognostic Value of FDG PET/CT Parameters for Patients with Surgically Treated Head and Neck Cancer: A Systematic Review. JAMA Otolaryngol. Head Neck Surg. 2020, 146, 471-479. [CrossRef] [PubMed]

203. Guha, A.; Connor, S.; Anjari, M.; Naik, H.; Siddiqui, M.; Cook, G.; Goh, V. Radiomic analysis for response assessment in advanced head and neck cancers, a distant dream or an inevitable reality? A systematic review of the current level of evidence. Br. J. Radiol. 2020, 93, 20190496. [CrossRef] [PubMed]

204. Salvatore, C.; Roberta, F.; Angela, L.; Cesare, P.; Alfredo, C.; Giuliano, G.; Giulio, L.; Giuliana, G.; Maria, R.G.; Paola, B.M.; et al. Clinical and laboratory data, radiological structured report findings and quantitative evaluation of lung involvement on baseline chest CT in COVID-19 patients to predict prognosis. Radiol. Med. 2021, 126, 29-39. [CrossRef]

205. Alessandrino, F.; Cristiano, L.; Cinnante, C.M.; Tartaglione, T.; Gerevini, S.; Verdolotti, T.; Colafati, G.S.; Ghione, E.; Vitale, R.; Peverelli, L.; et al. Value of structured reporting in neuromuscular disorders. Radiol. Med. 2019, 124, 628-635. [CrossRef] [PubMed]

206. Cornacchia, S.; Errico, R.; Balzano, R.F. Medical radiological procedures: Which information would be chosen for the report? Radiol. Med. 2019, 124, 783-793. [CrossRef] [PubMed] 